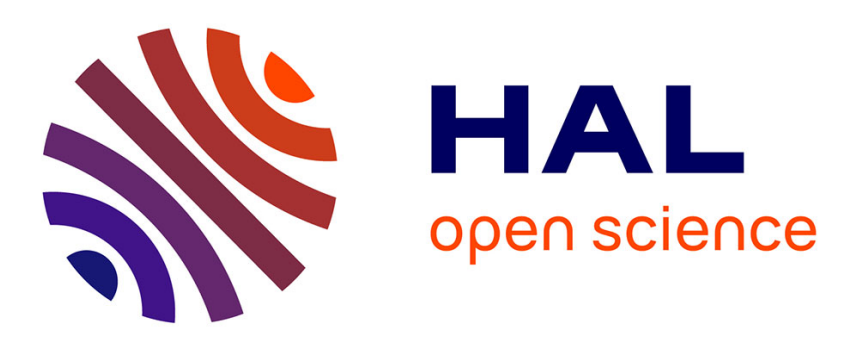

\title{
Carboxylic acid derivatives via catalytic carboxylation of unsaturated hydrocarbons: whether the nature of a reductant may determine the mechanism of $\mathrm{CO} 2$ incorporation?
}

\author{
E. Kirillov, J.-F. Carpentier, E Bunel
}

\section{To cite this version:}

E. Kirillov, J.-F. Carpentier, E Bunel. Carboxylic acid derivatives via catalytic carboxylation of unsaturated hydrocarbons: whether the nature of a reductant may determine the mechanism of CO2 incorporation?. Dalton Transactions, 2015, 44 (37), pp.16212-16223. 10.1039/c5dt02350e. hal01188186

\section{HAL Id: hal-01188186 \\ https://hal-univ-rennes1.archives-ouvertes.fr/hal-01188186}

Submitted on 24 Mar 2016

HAL is a multi-disciplinary open access archive for the deposit and dissemination of scientific research documents, whether they are published or not. The documents may come from teaching and research institutions in France or abroad, or from public or private research centers.
L'archive ouverte pluridisciplinaire HAL, est destinée au dépôt et à la diffusion de documents scientifiques de niveau recherche, publiés ou non, émanant des établissements d'enseignement et de recherche français ou étrangers, des laboratoires publics ou privés. 


\section{Carboxylic Acid Derivatives via Catalytic Carboxylation of Unsaturated Hydrocarbons:}

\section{Whether the Nature of Reductant May Determine the Mechanism of $\mathrm{CO}_{2}$ Incorporation?}

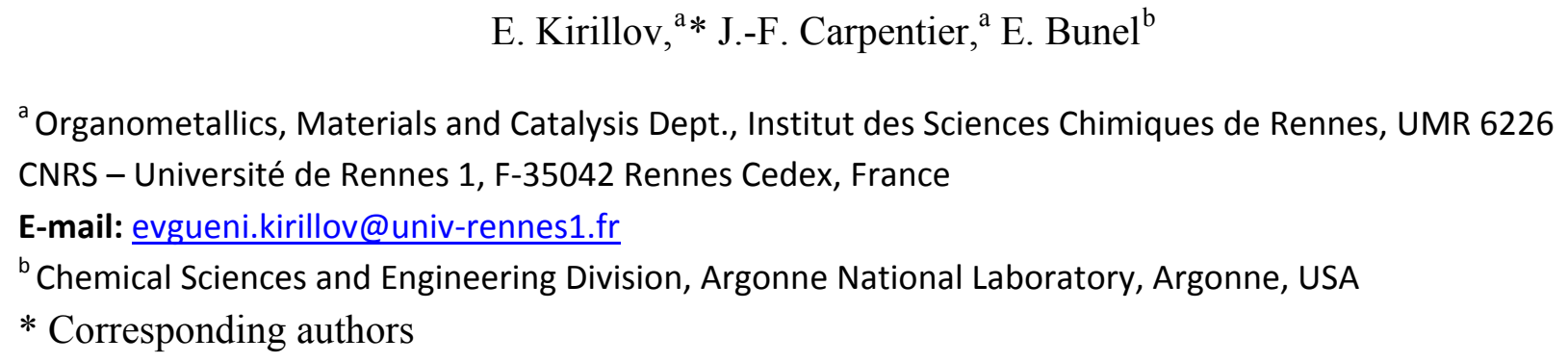

Abstract. Application of $\mathrm{CO}_{2}$ as a renewable feedstock and $\mathrm{C} 1$ building block for production of commodity and fine chemicals is a highly challenging but obvious industry-relevant task. Of particular interest is the catalytic coupling of $\mathrm{CO}_{2}$ with inexpensive unsaturated hydrocarbons (olefins, dienes, styrene, alkynes), providing direct access to carboxylic acids and their derivatives. Although not brand new for the scientific community, it is still a complete challenge, as no truly effective catalytic system has been reported to date. In this Perspective, we discuss the available experimental, theoretical and mechanistic data for such homogeneously catalyzed carboxylation processes. A special focus is placed on the understanding of the key elementary steps and of some thermodynamic and kinetic constraints.

\section{Introduction}

In a global context aiming at a more sustainable development, catalytic activation of $\mathrm{CO}_{2}$ mediated by transition metal complexes with complete integration of the whole $\mathrm{CO}_{2}$ molecules into

a Organometallics, Materials and Catalysis Dept., Institut des Sciences Chimiques de Rennes, UMR 6226 CNRS - Université de Rennes 1, F-35042 Rennes Cedex, France

Corresponding author: evgueni.kirillov@univ-rennes1.fr

${ }^{\mathrm{b}}$ Chemical Sciences and Engineering Division, Argonne National Laboratory, Argonne, IL 603494837, United States 
the final products has become a highly topical research area. Many international leading research groups have been working on such catalytic $\mathrm{CO}_{2}$ conversion into valuable chemicals, or on general methods for fixation of $\mathrm{CO}_{2}$. Besides two very recent major contributions, ${ }^{1}$ many reviews have been released on topics relevant to catalytic $\mathrm{CO}_{2}$ transformation and its utilization as $\mathrm{C} 1$ building block. $^{2}$ Reactions of particular interest include catalytic reduction (hydrogenation, hydrosilylation) of $\mathrm{CO}_{2},{ }^{3}$ synthesis of carboxylic acids, ${ }^{4}$ of acrylic acid derivatives from olefins/alkynes, ${ }^{5}$ and of polycarbonates from epoxides; ${ }^{6}$ also, much work has been devoted to computational aspects of some catalytic reactions implying $\mathrm{CO}_{2},{ }^{7}$ the stoichiometric chemistry of $\mathrm{CO}_{2}{ }^{8}$ and of other processes. $^{9}$

Among the above processes, formation of $\mathrm{C}-\mathrm{C}$ bonds by carboxylation of readily available unsaturated hydrocarbons (alkenes, dienes, styrenics, alkynes) offers a direct access to valuable saturated and unsaturated carboxylic acids and their derivatives. ${ }^{10}$ Modern industrial processes for production of carboxylic acids do not involve reactions with $\mathrm{CO}_{2}$. Only the Monsanto/Cativa processes implicate indirectly $\mathrm{CO}_{2}$ as a component for the water-gas shift reaction. Otherwise, carboxylic acids and their derivatives are traditionally synthesized by multi-step oxidation protocols starting from petrochemicals (propylene, butadiene, toluene, xylenes, naphthalene) or by carbonylation of alkenes with $\mathrm{CO} / \mathrm{H}_{2} \mathrm{O}$-alcohols (e.g. Koch acids, Reppe chemistry, hydroesterifications (Lucite process)). ${ }^{11}$ The direct catalytic carboxylation of unsaturated hydrocarbons bestows, in principle, obvious benefits in terms of energy and raw materials with respect to regular multistep oxidation protocols. This is fundamentally different from other activation processes implying severe reduction of $\mathrm{CO}_{2}$ (sometimes complete when hydrocarbonstype products are targeted), which are highly energy-intensive (reduction of $\mathrm{C}=\mathrm{O}$ bonds) and inherently poorly atom-efficient.

This Perspective article discusses a few existing strategies for the direct coupling of unsaturated hydrocarbons (alkenes, alkynes) with $\mathrm{CO}_{2}$ towards carboxylic acids.; a special attention is drawn to potential catalytic processes enabling the atom-economic reductive carboxylation of 
alkenes (Scheme 1). The article is focused on unraveling the essential problems of catalytic coupling of $\mathrm{CO}_{2}$ with unsaturated hydrocarbons and it analyzes the available information about the nature of key intermediates and side-products of the operative (actual and putative) catalytic mechanisms.

$$
\begin{aligned}
& \geqslant \mathrm{R}+\mathrm{CO}_{2} \underset{\substack{\text { reductant } \\
\text { Red-H }}}{[\text { Cat] }} \mathrm{H} \mathrm{H}_{\mathrm{O}}^{\mathrm{H}}{ }_{\mathrm{Red}}^{\mathrm{O}} \\
& \text { Red }=H ; M X_{n} \text { (inorganic salt or organometallic reagent of groups 1,2 metals); } \\
& \mathrm{SiR}_{3-\mathrm{n}}
\end{aligned}
$$

Scheme 1. Catalytic reductive carboxylation of unsaturated hydrocarbons into carboxylic acids and esters.

\section{State-of-the-Art and Main Features of Carboxylation of Unsaturated Hydrocarbons}

\subsection{Some Thermodynamic Considerations}

The high thermodynamic stability of $\mathrm{CO}_{2}$ makes unfavorable its conversion to other molecules; ${ }^{7 \mathrm{a}, 12}$ therefore, the corresponding processes require significant energy input in a form of heat, ${ }^{13}$ or, more common, as highly energetic co-reagents. For instance, some non-extensive thermochemical calculations on relevant reactions involving $\mathrm{CO}_{2}$ (Table 1) demonstrated that formation of the corresponding acids from $\mathrm{CO}_{2}$ and alkane/alkene is generally an endothermic process (reactions (2) and (3), respectively). Yet, although a significant thermodynamic constraint is also characteristic for the reduction of $\mathrm{CO}_{2}$ with $\mathrm{H}_{2}$ into formic acid (reaction (1)), the related reaction conducted in the presence of ethylene, to deliver eventually propionic acid, is calculated to be quite thermodynamically favorable (reaction (7)). Because a saturated acid forms in the latter coupling reaction, the corresponding energy is virtually driven by the exergonic ethylene hydrogenation reaction (4). Similarly, highly negative enthalpies and Gibbs energies are estimated 
for the reactions implying strong reductants such as hydrosilanes or hydroboranes (reactions (8)-(11)), which provide the corresponding carboxylic acids esters.

Table 1. Calculated Enthalpies and Free Energies (in $\mathrm{kcal} \cdot \mathrm{mol}^{-1}$ ) for some basic reactions implying $\mathrm{CO}_{2}$ and ethylene. ${ }^{a}$

\begin{tabular}{|c|c|c|}
\hline Reaction & $\Delta \mathrm{H}$ & $\Delta \mathrm{G}$ \\
\hline 1. $\mathrm{CO}_{2}+\mathrm{H}_{2} \rightarrow \mathrm{HCOOH}$ & $\begin{array}{c}+7.4 \\
(+5.1)^{b}\end{array}$ & $\begin{array}{c}+12.5 \\
(+12.0)\end{array}$ \\
\hline 2. $\mathrm{CO}_{2}+\mathrm{CH}_{3} \mathrm{CH}_{3} \rightarrow \mathrm{CH}_{3} \mathrm{CH}_{2} \mathrm{COOH}$ & +9.7 & +16.9 \\
\hline 3. $\mathrm{CO}_{2}+\mathrm{CH}_{2}=\mathrm{CH}_{2} \rightarrow \mathrm{CH}_{2}=\mathrm{CHCOOH}$ & $\begin{array}{c}+5.8 \\
(+5.7)^{b}\end{array}$ & $\begin{array}{c}+20.4 \\
(+18.0)^{b}\end{array}$ \\
\hline 4. $\mathrm{CH}_{2}=\mathrm{CH}_{2}+\mathrm{H}_{2} \rightarrow \mathrm{CH}_{3} \mathrm{CH}_{3}$ & -36.3 & -23.4 \\
\hline 5. $\mathrm{CH}_{2}=\mathrm{CH}_{2}+\mathrm{Et}_{3} \mathrm{SiH} \rightarrow \mathrm{Et}_{4} \mathrm{Si}$ & -32.6 & -15.3 \\
\hline 6. $\mathrm{CH}_{2}=\mathrm{CH}_{2}+\mathrm{HBpin} \rightarrow$ EtBpin & -35.6 & -19.3 \\
\hline 7. $\mathrm{CO}_{2}+\mathrm{CH}_{2}=\mathrm{CH}_{2}+\mathrm{H}_{2} \rightarrow \mathrm{CH}_{3} \mathrm{CH}_{2} \mathrm{COOH}$ & -26.7 & -7.5 \\
\hline 8. $\quad \mathrm{CO}_{2}+\mathrm{Et}_{3} \mathrm{SiH} \rightarrow \mathrm{HCOOSiEt}_{3}$ & -16.0 & -11.7 \\
\hline 9. $\mathrm{CO}_{2}+\mathrm{HBpin} \rightarrow \mathrm{HCOOBpin}$ & -14.8 & -5.0 \\
\hline 10. $\mathrm{CO}_{2}+\mathrm{CH}_{2}=\mathrm{CH}_{2}+\mathrm{Et}_{3} \mathrm{SiH} \rightarrow \mathrm{CH}_{3} \mathrm{CH}_{2} \mathrm{COOSiEt}_{3}$ & -49.9 & -23.4 \\
\hline 11. $\mathrm{CO}_{2}+\mathrm{CH}_{2}=\mathrm{CH}_{2}+\mathrm{HBpin} \rightarrow \mathrm{CH}_{3} \mathrm{CH}_{2} \mathrm{COOBpin}$ & -48.3 & -21.7 \\
\hline
\end{tabular}

The above thermochemical estimations unequivocally illustrate the feasibility of alkene carboxylation reactions towards the corresponding carboxylic acids or some of their derivatives, provided they are carried out in the presence of an appropriate reducing agent $\left(\mathrm{H}_{2}\right.$ or hydrosilane/hydroborane, respectively). Thus, a quest for elaboration of new systems competent for catalyzing these processes has been ongoing.

\subsection{Direct carboxylation of unsaturated hydrocarbons (alkenes, alkynes, dienes) to} carboxylic acids. Role of the (reverse) water-gas shift reaction ((r)WGSR).

Straightforward production of carboxylic acids from parent alkenes can be realized via two principal catalytic ways - hydrocarboxylation and hydroxycarbonylation -, both of them using end- 
products of the water-gas shift reaction (WGSR), ${ }^{14}$ namely, $\mathrm{CO} / \mathrm{H}_{2} \mathrm{O}$ and $\mathrm{CO}_{2} / \mathrm{H}_{2}$ combinations, respectively.

It has been previously disclosed that carboxylic acids (as mixtures of linear and branched products) can be obtained via Pd-catalyzed hydroxycarboxylation of $\alpha$-olefins with $\mathrm{CO} / \mathrm{H}_{2} \mathrm{O} .{ }^{15}$ The so-called hydride mechanism, elucidated by Van Leeuwen and coworkers (Scheme 2), ${ }^{16}$ presumed that the Pd-acyl species, formed via insertion of $\mathrm{CO}$ into the Pd-alkyl intermediate, reacts with $\mathrm{H}_{2} \mathrm{O}$ eliminating the corresponding carboxylic acid and, thus, regenerating the catalyst. In spite of the obvious thermodynamic preference of the WGSR $\left(\Delta H=-9.8 \mathrm{kcal} \cdot \mathrm{mol}^{-1}\right){ }^{14}$ this step (even if operational) seemed not to play any crucial role in the process. ${ }^{16,17}$

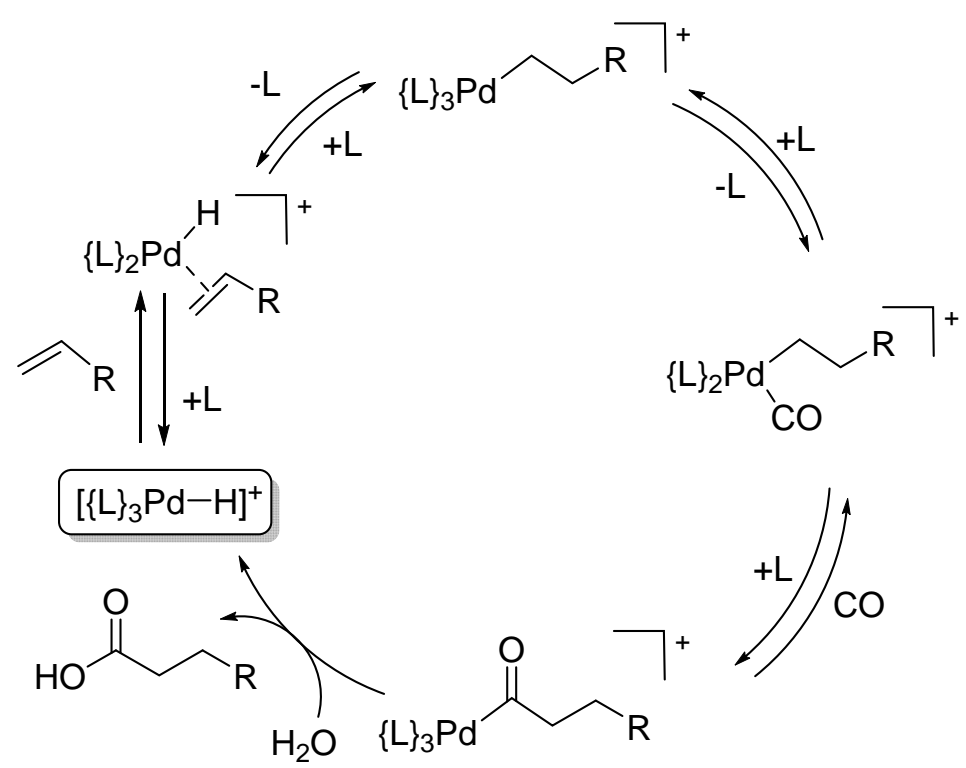

Scheme 2. Proposed mechanism for the Pd catalyzed hydroxycarbonylation of olefins with $\mathrm{CO} / \mathrm{H}_{2} \mathrm{O}$ (only formation of the linear product is illustrated). ${ }^{16}$

On the other hand, there are only a few reports disclosing the straightforward synthesis of carboxylic acids from $\mathrm{CO}_{2}$. In seminal contributions, it has been demonstrated that the "direct" carboxylation of ethylene with $\mathrm{CO}_{2}$, mediated by homogeneous catalytic systems $\left(\left(\mathrm{Ph}_{3} \mathrm{P}\right)_{2} \mathrm{PdCl}{ }_{2} / \mathrm{HCl}\right.$ or $\left.\left(\mathrm{Ph}_{3} \mathrm{P}\right)_{3} \mathrm{RhCl} / \mathrm{HBr}\right)$, required very harsh conditions $\left(120-180{ }^{\circ} \mathrm{C}, 150-700\right.$ 
atm) and resulted in the formation of propionic acid in 38\% yield, with ethanol and ethyl propionate as the major byproducts. ${ }^{18}$

Very recently, another catalytic protocol for hydrocarboxylation of both linear and cyclic alkenes has been disclosed by Leitner et al; ${ }^{19}$ this one uses $\left[\mathrm{RhCl}(\mathrm{CO})_{2}\right]_{2} / \mathrm{PPh}_{3} / p-\mathrm{TsOH} \cdot \mathrm{H}_{2} \mathrm{O}$ as precatalysts coupled with $\mathrm{CH}_{3} \mathrm{I}$ as promoter and $\mathrm{H}_{2}$ as hydrogen source/reductant. In this case, the proposed catalytic cycle incorporates two interlinked loops (Scheme 3): the first one sets up an equilibrium between $\mathrm{CO}_{2} / \mathrm{H}_{2}$ and $\mathrm{CO} / \mathrm{H}_{2} \mathrm{O}$ through a reverse water-gas shift reaction (rWGSR), while the second one leads to formation of a Rh-alkyl intermediate, followed by a carbonylation reaction sequence. The intrinsic feature of this mechanism is the absence of carboxylate intermediates, as well as that the principal hydroxycarbonylation cycle parallels the one of the mechanism of hydroxycarboxylation using $\mathrm{CO} / \mathrm{H}_{2} \mathrm{O} .{ }^{16}$ The overall reaction occurs in acetic acid under, however, still drastic conditions (60 bar $\mathrm{CO}_{2}, 10$ bar $\left.\mathrm{H}_{2}, 180{ }^{\circ} \mathrm{C}\right)$.

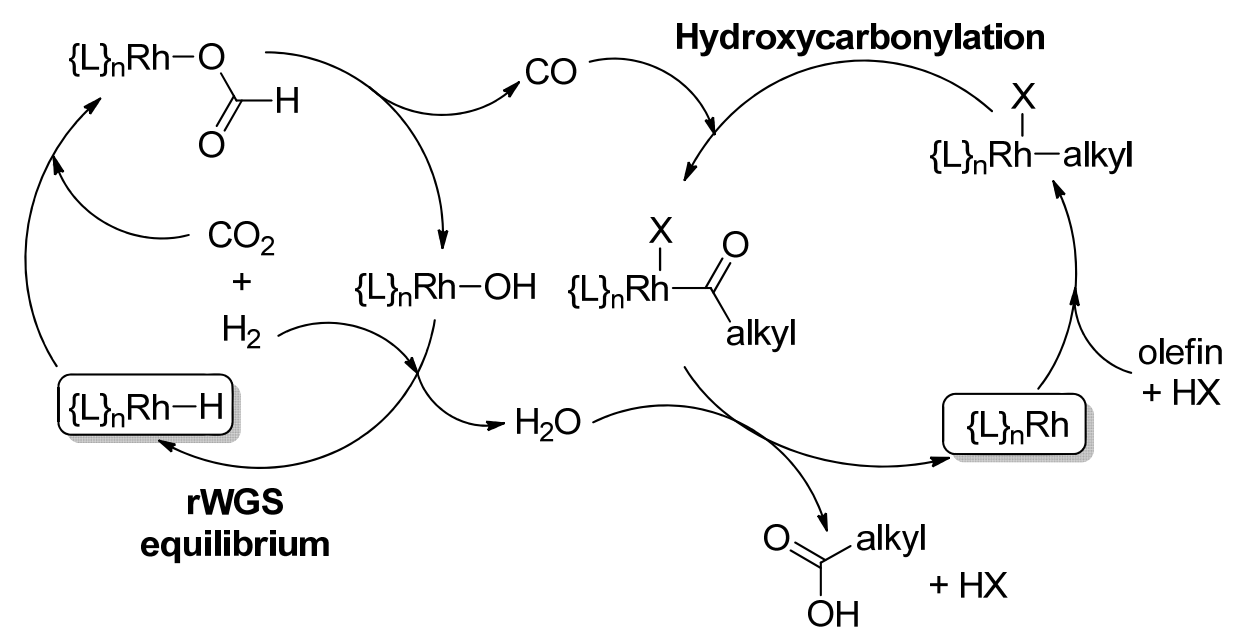

Scheme 3. Proposed mechanism for the Rh-catalyzed hydroxycarbonylation-"hydrocarboxylation" of olefins. $^{19}$

Interestingly, under virtually similar conditions $\left(\mathrm{CO}_{2} / \mathrm{H}_{2}, 30-60\right.$ bar, $130-140{ }^{\circ} \mathrm{C}, \mathrm{NMP}$ as solvent and Li salts as additive) upon using $\mathrm{H}_{4} \mathrm{Ru}(\mathrm{CO})_{12}{ }^{20}$ and $\mathrm{Ru}_{3}(\mathrm{CO})_{12} /$ phosphine ${ }^{21}$ as catalysts, 
domino hydroformylation/reduction reactions of alkenes have been observed, which resulted in isolation of the corresponding alcohols (mixtures of linear and branched products). The possible intermediacy of the carboxylic acid formation step for these processes has not been established.

Yet, electrochemical coupling of $\mathrm{CO}_{2}$ with $\alpha$-olefins (propylene and 1-butene) mediated by $\mathrm{Ni}$ (II) complexes has been reported to afford mixtures of two major products, namely, a substituted succinic acid and the corresponding unsaturated monocarboxylic acid (Scheme 4). ${ }^{22}$ Under the same conditions, butadiene has been transformed into a mixture of mono- and dicarboxylic acids: predominantly, 3-pentenoic, 2-ethenyl-succinic and cis-/trans-3-hexene-1,6-dioic acids. The mechanism of formation of these products remains unclear. By a similar electroreductive coupling of both terminal and internal alkynes and $\mathrm{CO}_{2}$, catalyzed by $\mathrm{Ni}$ complexes, unsaturated carboxylic acids have been prepared. ${ }^{23}$

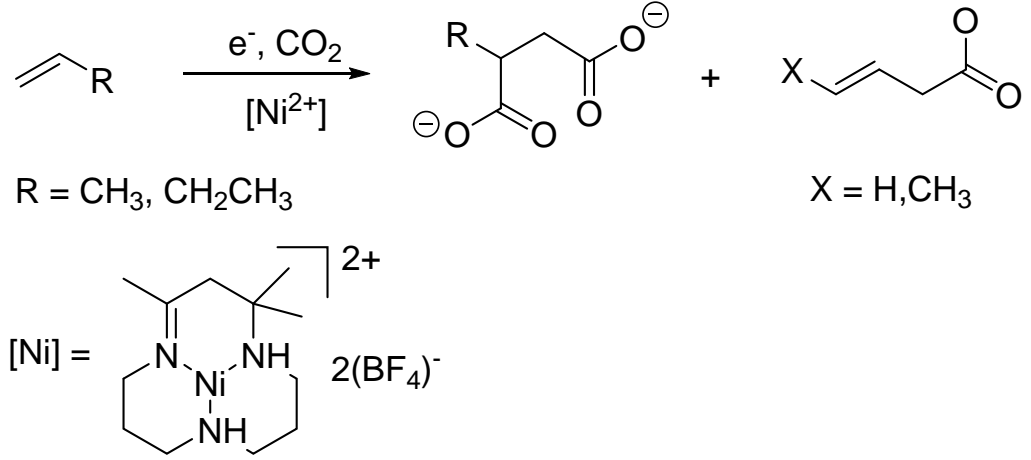

Scheme 4. Ni-catalyzed electrocarboxylation of propylene and 1-butene. ${ }^{22}$

Benzonitrile-promoted electrocarboxylation of styrene into 3-phenylpropionic acid has been also documented to operate presumably via a radical mechanism. ${ }^{24}$

\subsection{Acrylates from alkenes and $\mathrm{CO}_{2}$ : from stoichiometric studies towards catalysis}

The catalytic coupling of alkenes with $\mathrm{CO}_{2}$ to produce acrylic acids ${ }^{25}$ has long been of interest from both fundamental and industrial points of view. In pioneering studies aimed at 
identifying potential catalytic pathways for the straightforward production of acrylic acid from ethylene and $\mathrm{CO}_{2}$, several $\mathrm{Ni}$ and $\mathrm{Pd}$ complexes have been recognized as effective precatalysts. The key step of such catalytic processes is presumably the oxidative coupling reaction of the alkene with $\mathrm{CO}_{2}$ onto low valent metal centers in the catalytically active species, which affords metallacyclic product 1-M (Scheme 5). ${ }^{26,27}$ Such intermediacy has been experimentally established for $\mathrm{Ni}(0),{ }^{28} \mathrm{Fe}(0)^{29}$ and $\mathrm{Pd}(0)^{30}$ (with dienes) precursors in the pioneering studies of Hoberg and coworkers and others. ${ }^{31,32,33}$

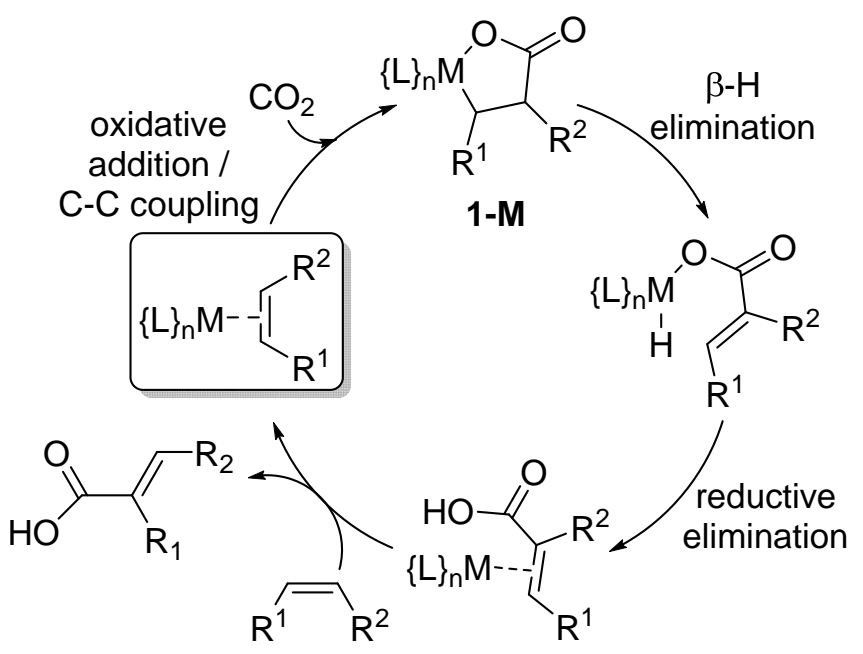

Scheme 5. Hypothetic mechanism for the synthesis of acrylic acids from alkenes and $\mathrm{CO}_{2}$ via formation of metallalactone 1-M $(\mathrm{M}=\mathrm{Ni}, \mathrm{Fe}){ }^{28,29}$

While it had been proposed that the metallalactone derivative 1-M can follow $\beta-\mathrm{H}$ and reductive elimination reactions giving rise to the corresponding acrylic acid (Scheme 4), it has eventually appeared that the metallacycles are essentially robust; in fact, cleavage of the $\mathrm{M}-\mathrm{O}$ and $\mathrm{M}-\mathrm{C}$ bonds does not occur without decomposition of these complexes. Only in one case, transformation of several nickelalactone complexes into hydrido-acrylate and then into acrylate derivatives, however without further reductive elimination step, induced by addition of dppm ligand, has been documented. ${ }^{34}$ 
It has been experimentally demonstrated that some additional components can provoke release of the carboxylic fragment (Scheme 6). For instance, acidic hydrolysis yielded the corresponding carboxylic acid (Scheme 6, eq (1)), while treatment of nickelalactone 1-Ni with $\mathrm{CH}_{3} \mathrm{OH}$ under acidic conditions provided the corresponding ester (eq (2)). ${ }^{28 b, d, 35}$ In particular, stoichiometric reactions of 1-Ni with ethylene, styrenes and other functionalized alkenes (eq (3)) followed by hydrolysis resulted in isolation of mainly linear carboxylic acids. ${ }^{36}$ In this case, it was proposed that the insertion of the substrate $\mathrm{C}=\mathrm{C}$ double bond into the $\mathrm{Ni}-\mathrm{C}$ bond of $\mathbf{1}-\mathrm{Ni}$ resulted in the ring expansion of the five-membered metallacycle, the derived thereof seven-membered intermediate being more prone for $\beta-\mathrm{H}$ elimination reaction. The reductive elimination reaction towards the corresponding carboxylic acid and regeneratation of the $\{\mathrm{L}\}_{\mathrm{n}} \mathrm{Ni}(0)$ catalytic species appeared, however, to be unfavorable for the above systems, which hampered catalytic turnover; nonetheless, this step was found operational for the Pd- and Ni-catalyzed catalytic coupling of $\mathrm{CO}_{2}$ with dienes (functionalization/telomerization) ${ }^{37}$ or with diynes. $^{38}$

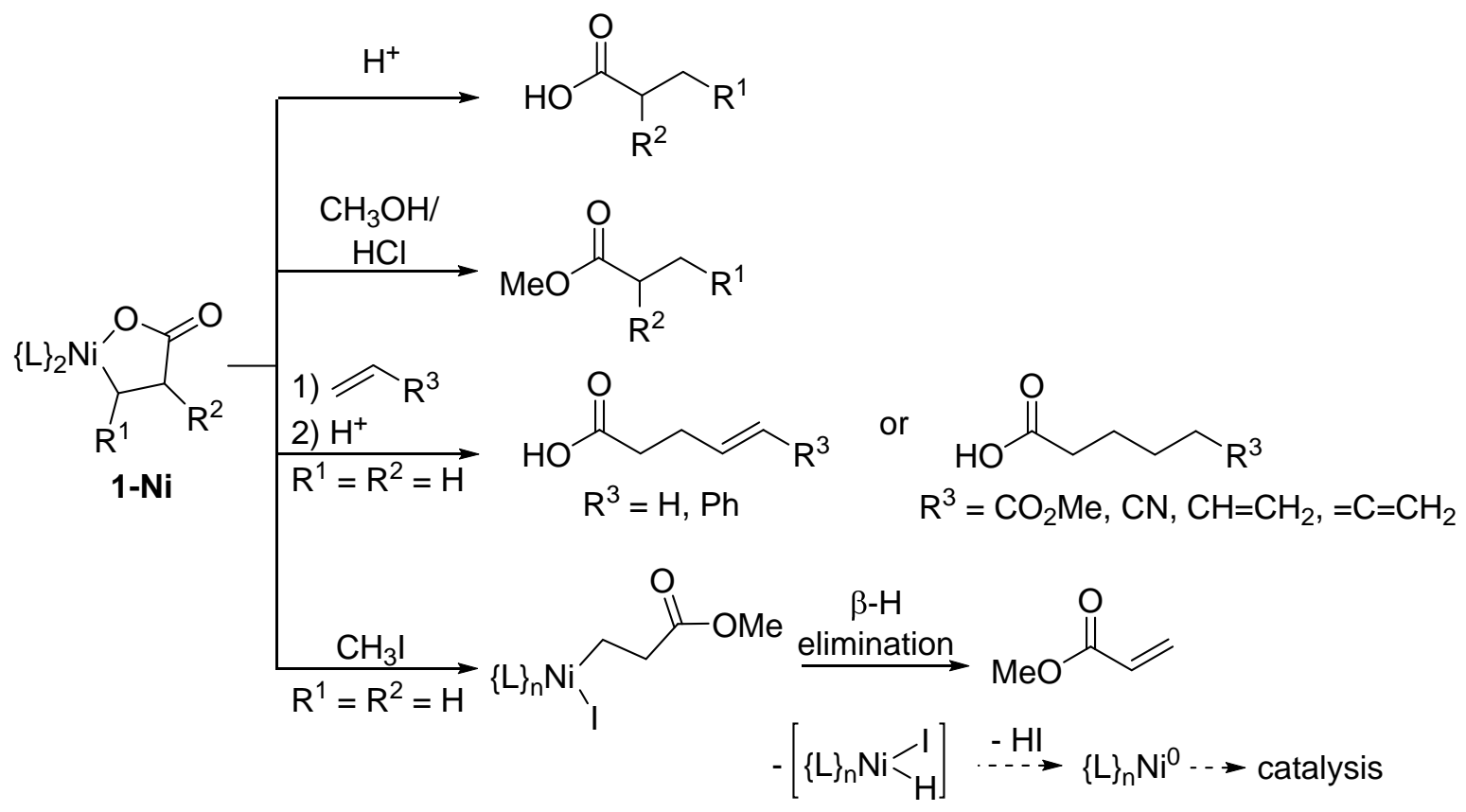

Scheme 6. Stoichiometric reactions of nickelalactones 1-Ni. 
As demonstrated by DFT studies, ${ }^{39}$ the direct $\beta-\mathrm{H}$ elimination reaction from metallalactone 1-Ni $(\mathrm{L}=\mathrm{DBU})$, which would have resulted in formation of a metal-hydrido-acrylate intermediate (Scheme 5), is not only kinetically problematic (computed $\Delta G^{\neq}{ }_{298}=c a .40 \mathrm{kcal} \cdot \mathrm{mol}^{-1}$ ) but also thermodynamically unfavorable (computed $\Delta G_{298}=c a .+10 \mathrm{kcal} \cdot \mathrm{mol}^{-1}$ ). Moreover, the subsequent reductive elimination step involving coupling of the metal-hydride and acrylate groups was also found to feature a high activation barrier, which, depending on the mechanism of elimination, can vary between 20 and $40 \mathrm{kcal} \cdot \mathrm{mol}^{-1}$. It has been predicted for the given system that preliminary cleavage of the $\mathrm{Ni}-\mathrm{O}$ bond and decoordination of the carboxylate group can release the ring strain and stabilize the transition state leading to $\beta-\mathrm{H}$ elimination. This estimate has been further corroborated experimentally by Rieger and coworkers ${ }^{40}$ and others ${ }^{41}$ on the reactions between unsubstituted nickelalactones 1-Ni bearing different ligands $\mathrm{L}$ with an excess of $\mathrm{CH}_{3} \mathrm{I}$ as the metallalactone cleaving agent (Scheme 6, eq (4)). However, the low yields (2-56\% vs Ni) of methyl acrylate product over 3-48 h and significant concomitant decomposition of the Ni species make these reactions catalytically impractical so far. Additional insights in the nature of possible intermediates in this process and hypothetic decomposition pathways have been recently gained from combined computational ${ }^{42}$ and experimental studies. ${ }^{43}$ For example, for the reactions involving $\mathrm{CH}_{3} \mathrm{I}$ as co-reagent, the corresponding activation barrier $\Delta G^{\neq}{ }_{298}$ for the $\beta$ - $\mathrm{H}$ elimination of methyl acrylate was computed in the reasonable range $15-25 \mathrm{kcal} \cdot \mathrm{mol}^{-1}$ (depending on the theoretical method and model). On the other hand, a high endothermicity $\left(\Delta G_{298}=+5-25\right.$ $\mathrm{kcal} \cdot \mathrm{mol}^{-1}$ ) was computed for the $\mathrm{HI}$ reductive elimination step (which can in principle be surmounted by an introduction of a base), required to regenerate a $\{\mathrm{L}\}_{n} \mathrm{Ni}(0)$ catalyst; this set up another obstacle for catalytic turnover.

By analogy, addition of stoichiometric amounts of different reagents $\left(\mathrm{B}\left(\mathrm{C}_{6} \mathrm{~F}_{5}\right)_{3},{ }^{44} \mathrm{Na}^{+}[\mathrm{B}(\mathrm{m}-\right.$ $\left.\left.\left.\left(\mathrm{CF}_{3}\right)_{2} \mathrm{Ph}\right)_{4}\right]^{-45} \mathrm{X}_{2}(\mathrm{X}=\mathrm{Cl}, \mathrm{Br}, \mathrm{I}),{ }^{46} \mathrm{Ph}_{2} \mathrm{Zn}^{47}\right)$ to $\mathbf{1 - N i}$ complexes has been shown to eventually promote cleavage of the nickelalactone cycle and elimination of the acrylate fragment. 
Yet, the carboxylation reactions of $\mathrm{Mo}(0)$ - and $\mathrm{W}(0)$-ethylene complexes, affording the corresponding acrylates $\mathbf{2}$ and 3, originally reported by Carmona and coworkers, constitute another model for coupling of $\mathrm{CO}_{2}$ with olefins (Scheme 7). ${ }^{48}$ As proposed from DFT calculations, the formation of 2-W and 3-W is intermediated by formation of a metallacyclic species analogous to 1M. ${ }^{49}$ Thus, the corresponding barrier for the $\beta-\mathrm{H}$ elimination reaction yielding $2-\mathbf{W}$ and $3-\mathbf{W}$ was estimated to be significantly lower (computed $\Delta E^{\neq}{ }_{298}=c a .10 \mathrm{kcal} \cdot \mathrm{mol}^{-1}$ ) than those typically found in Ni-based systems.

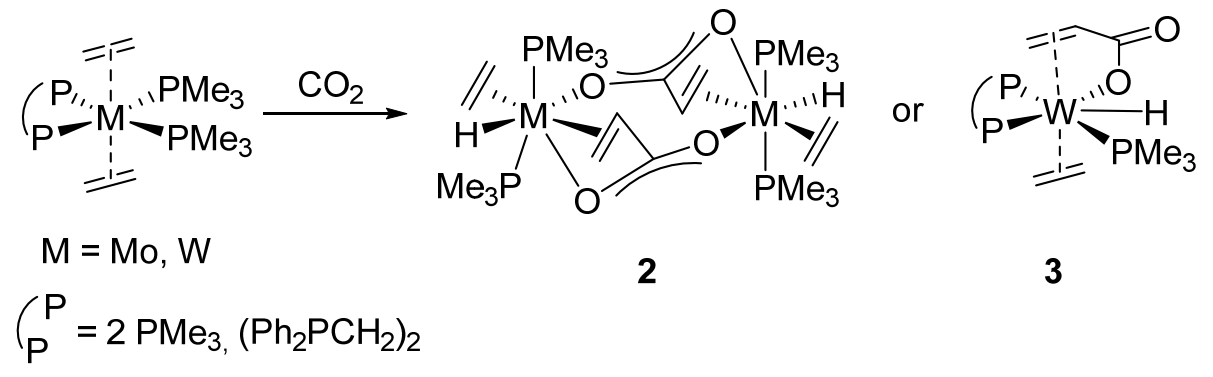

Scheme 7. Reaction between $\mathrm{Mo}(0)$ - and $\mathrm{W}(0)$-ethylene complexes and $\mathrm{CO}_{2}{ }^{48}$

Of particular interest is the reactivity of hydride complex (Triphos) $\mathrm{MoH}_{4}\left(\mathrm{PPh}_{3}\right)($ Triphos $=$ $\left.\left.\mathrm{Ar}_{2} \mathrm{PCH}_{2} \mathrm{CH}_{2}\right)_{2} \mathrm{PPh} ; \mathrm{Ar}=\mathrm{Ph}\right)$ disclosed by Bernskoetter and coworkers (Scheme 8). ${ }^{50}$ Several products, formate, acrylate and propionate complexes can be derived from the corresponding precursor, the selectivity of the reaction depending on the ratio of the $\mathrm{C}_{2} \mathrm{H}_{4} / \mathrm{CO}_{2}$ feed. 


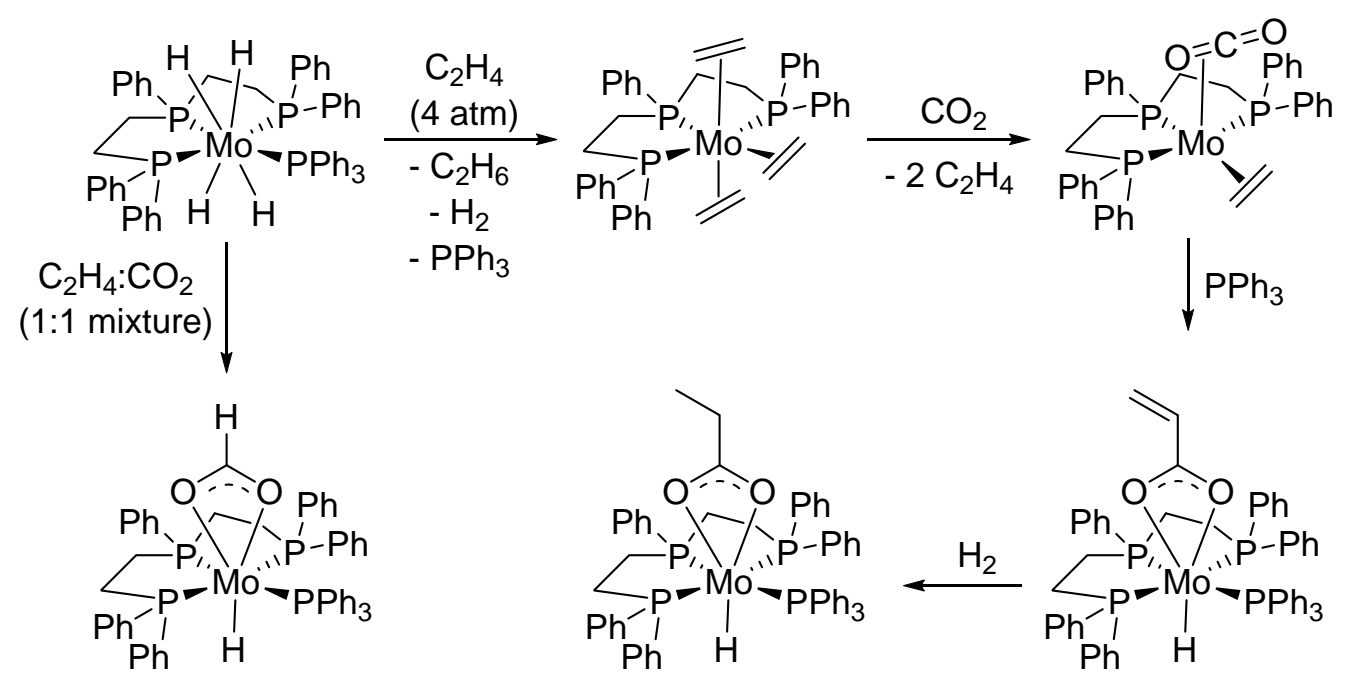

Scheme 8. Reactivity of (Triphos) $\mathrm{MoH}_{4}\left(\mathrm{PPh}_{3}\right)$ with ethylene and $\mathrm{CO}_{2}{ }^{50}$

Selective formation of similar acrylate products in reactions of zerovalent Mo-Triphos complexes (Triphos) $\mathrm{Mo}\left(\mathrm{C}_{2} \mathrm{H}_{4}\right)\left(\mathrm{N}_{2}\right)_{2}$ has been found to take place with different rates depending on the nature of aryl substituents on the ligand (the following rates order has been established: $\mathrm{Ph}>m$ $\left.\mathrm{Me}_{2}-\mathrm{Ph} \geq p-\mathrm{CF}_{3}-\mathrm{Ph}>p-\mathrm{Me}-\mathrm{Ph} \approx p-\mathrm{F}-\mathrm{Ph}>p-\mathrm{MeO}-\mathrm{Ph}>m-t \mathrm{Bu}_{2}-\mathrm{Ph}\right) .{ }^{51} \quad$ Yet, the above acyclic metal-hydrido-carboxylate products of Mo and W did not reveal any propensity to reductively eliminate the corresponding carboxylic acids. Alike 1-Ni, the monomeric tungsten acrylate $\left((\mathrm{MeO})_{3} \mathrm{P}\right)_{5} \mathrm{Mo}(\mathrm{H})\left(\mathrm{OC}(\mathrm{O}) \mathrm{CH}=\mathrm{CH}_{2}\right)$ upon treatment with $\mathrm{CH}_{3} \mathrm{I}$ slowly released methyl acrylate again with low yield. ${ }^{52}$

For a completely different system based on a cationic Pd-methoxycarbonyl complex (Scheme 9), it has been established that methyl acrylate is readily released upon exposure to an ethylene atmosphere under mild conditions (room temperature; 1 bar pressure). ${ }^{53}$ Nature of the solvent influenced the yield of the reaction; significantly better yields than those having been obtained in $\mathrm{CH}_{2} \mathrm{Cl}_{2} / \mathrm{MeCN}$ mixture or in neat $\mathrm{CH}_{2} \mathrm{Cl}_{2}$ were achieved in DMF. According to the DFT model, the essential role of DMF is the stabilization of intermediates and transition states via formation of relatively strong metal-solvent bonds that grants more favorable pathway in terms of free energy. The rate-determining step for this process was suggested to be the $\mathrm{C}-\mathrm{C}$ bond coupling 
reaction, that is, the insertion of ethylene into the $\mathrm{Pd}-\mathrm{C}$ bond of the methoxycarbonyl complex (computed $\Delta G^{\neq}{ }_{298}=26 \mathrm{kcal} \cdot \mathrm{mol}^{-1}$ ), while the $\beta-\mathrm{H}$ scission reaction from the open form of the alkyl-Pd intermediate featured a lower barrier (computed $\left.\Delta G^{\neq}{ }_{298}=17 \mathrm{kcal} \cdot \mathrm{mol}^{-1}\right)$.

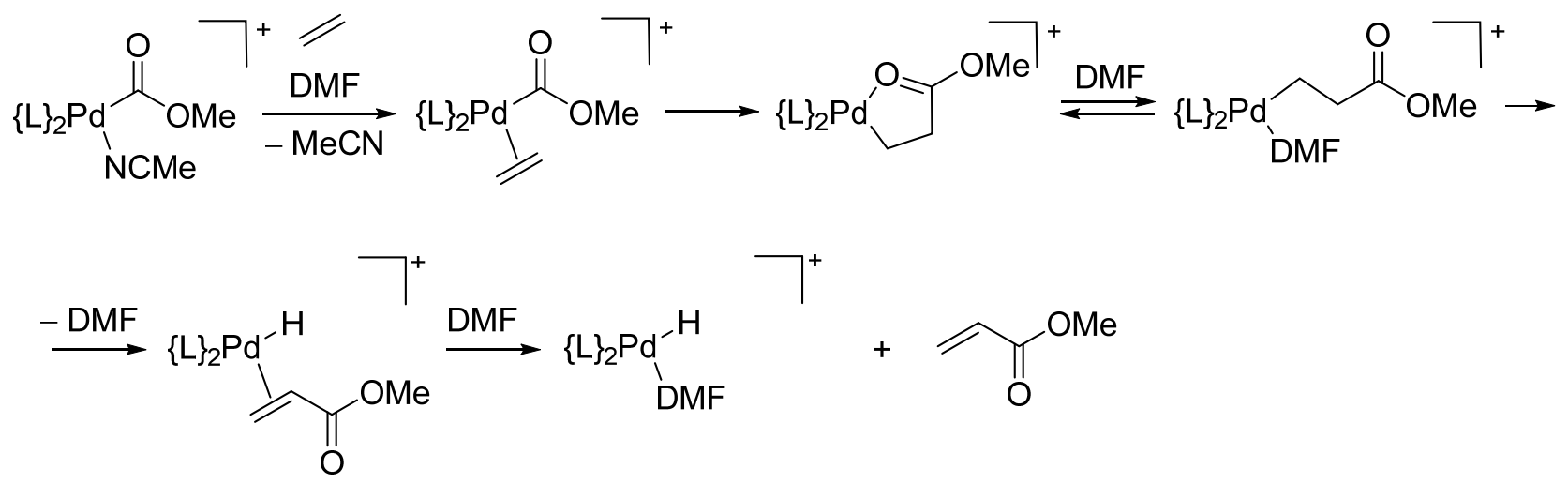

Scheme 9. Computed mechanism for methyl acrylate formation from the reaction of complex $\left[\{\mathrm{dppe}\}_{2} \mathrm{Pd}(\mathrm{COOMe})\right]^{+}\left[\mathrm{SO}_{3} \mathrm{CF}_{3}\right]^{-}$with ethylene in $\mathrm{DMF} .{ }^{53}$

Under somewhat more drastic conditions (30 bar ethylene, 30 bar $\mathrm{CO}_{2}$ ) complex $\left[\{\text { dppe }\}_{2} \mathrm{Pd}(\mathrm{COOMe})\right]^{+}\left[\mathrm{SO}_{3} \mathrm{CF}_{3}\right]^{-}$, along with stoichiometric production of methyl acrylate, has been found to catalyze the formation of ethyl acrylate. ${ }^{53}$ A putative mechanism involving the intermediacy of Pd-hydrido species was proposed (Scheme 10). However, the results of both stoichiometric and theoretical studies have ruled out the proposed mechanism. ${ }^{53}$ No alternative mechanism for this catalytic reaction matching the experimental observations has been suggested so far. 


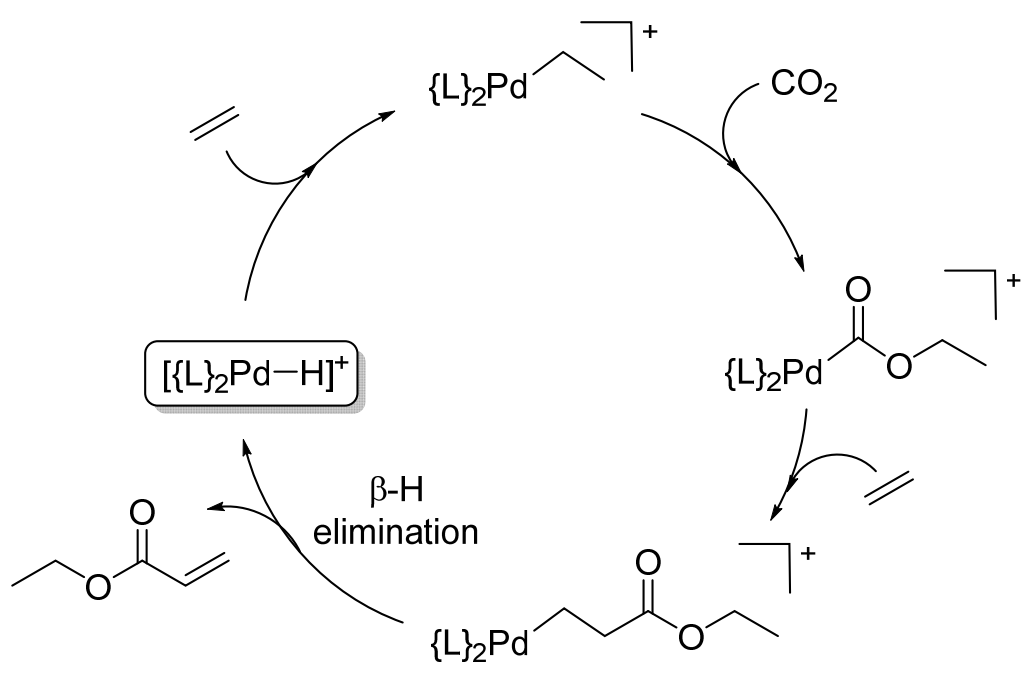

Scheme 10. Disclaimed putative hydride mechanism for Pd-catalyzed synthesis of ethyl acrylate from ethylene and $\mathrm{CO}_{2}{ }^{53}$

\subsection{Catalytic coupling of $\mathrm{CO}_{2}$ with alkenes/alkynes/dienes in the presence of} organic/organometallic substrates as reductants

The lack of catalytic activity systematically observed in the above studies about alkene carboxylation into acrylic acid derivatives, and also fundamental thermodynamic calculations, ${ }^{39}$ suggest unfavorable overall thermodynamics of this type of reaction. That is, the thermodynamic driving force of the coupling reaction of alkene with $\mathrm{CO}_{2}$ is directly related to the formation of a species with a strong $\mathrm{M}-\mathrm{O}$ bond (a metallalactone or a carboxylate), but release of a "free" carboxylic acid and regeneration of a reduced metal species, which is mandatory to enable the catalytic turnover, are disfavored.

A workaround has been identified, which consists in implementing in the reaction (super)stoichiometric amounts of "energetic" reactants (organometallics or related organoelementals) that compensate the initially unfavorable thermodynamics of the reaction by the more favored formation of the corresponding metal/organoelemental carboxylate derivatives, and simultaneously regenerate the low valent metal active species. 
A breakthrough along these lines has been achieved with alkoxy/phenoxy, amido and borate salts of $\mathrm{Na}$, which enabled the synthesis of sodium acrylates with a Ni-based catalytic system (Scheme 11); ${ }^{54}$ so far, the maximal TON reached ca. 100 (10 bar $\mathrm{CO}_{2}, 5$ bar ethylene, THF, 100 ${ }^{\circ} \mathrm{C} ; 300$ equiv $o-\mathrm{F}-\mathrm{C}_{6} \mathrm{H}_{4}-\mathrm{ONa}$ vs. Ni). As it has been corroborated by theoretical investigations, ${ }^{\text {Erreur ! Signet non défini.a, } 55}$ the key factor in this system is the presence of a base with high proton affinity (typically, $\mathrm{RO}^{-}$), which modifies a transition state leading to the $\beta-\mathrm{H}$ elimination reaction in the nickelalactone and reduces the barrier of this rate determining step (the corresponding calculated barrier $\Delta G^{\neq}{ }_{298}$ drops down to $12-16 \mathrm{kcal} \cdot \mathrm{mol}^{-1}$ ). Also, as long as the corresponding carboxylic acid is produced in a form of a sodium salt, this allows maintaining favorable thermodynamics of the global process (computed $\Delta G_{298}=c a .-15 \mathrm{kcal} \cdot \mathrm{mol}^{-1}$ ).
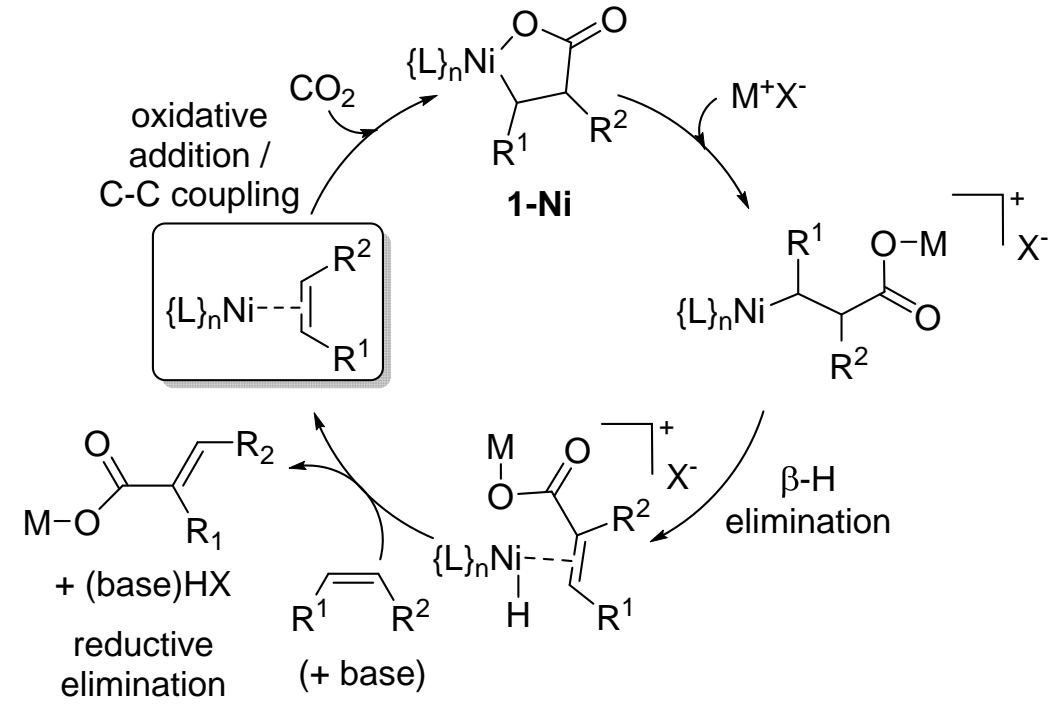

Scheme 11. Proposed mechanism for the Ni-catalyzed formation of acrylic acid derivatives from alkenes and $\mathrm{CO}_{2}$ in the presence of inorganic or organometallic salts $\mathrm{M}^{+} \mathrm{X}^{-}$(and an additional base). Erreur ! Signet non défini.

The first catalytic reductive hydrocarboxylation of styrenes under mild conditions ( 1 bar $\mathrm{CO}_{2}$; room temperature; THF), using an excess of $\mathrm{Et}_{2} \mathrm{Zn}$ as nucleophilic interceptor, ${ }^{56}$ has been 
successfully achieved by Rovis and coworkers. ${ }^{57}$ The NiR 2 /additive/Et ${ }_{2} \mathrm{Zn}(\mathrm{R}=1,5-\mathrm{COD}$, acac; additive $=\mathrm{Cs}_{2} \mathrm{CO}_{3}$, DBU, pyridine) catalytic system has been surmised to operate via a completely different mechanism, which excludes formation of nickelalactone intermediates and involves distinct hydrometallation and carboxylation steps leading regioselectively to saturated $\alpha$-substituted carboxylic acid derivatives (Scheme 12). Several limitations have been identified for the Ni-based system: (1) it is poorly active in carboxylation of both linear olefins, cyclic dienes and $\beta$-substituted styrenes; (2) the activity of the catalytic system strongly depends on the nature of the additive; 3 ) also, the nature of the reducing agent plays one of the key roles, as the system is not efficient if $\mathrm{Et}_{2} \mathrm{Zn}$ is replaced with $\mathrm{PrOH}, \mathrm{Ph}_{3} \mathrm{SiH}$ or $\mathrm{H}_{2}$, while $\mathrm{Me}_{2} \mathrm{Zn}$ and $\mathrm{Ph}_{2} \mathrm{Zn}$ afforded different products (no alkylated product and benzoic acid, respectively). Very recently, the mechanism has been computationally revisited, asserting transient Ni-hydrides as catalytically active species, whereas the other possible pathway involving formation of nickelalactone has been found to be kinetically disfavored. $^{58}$

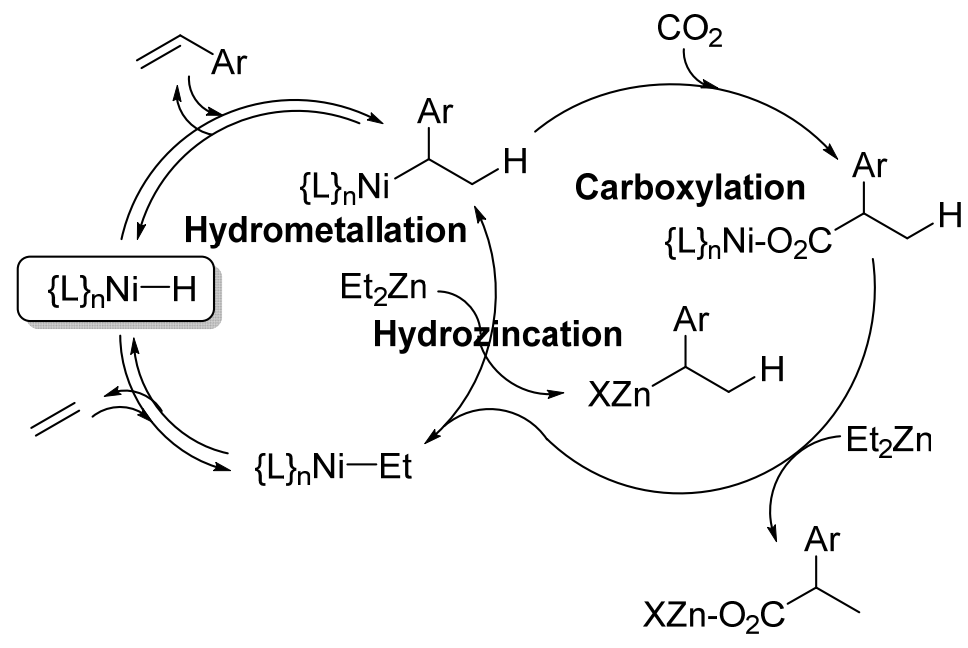

Scheme 12. Proposed mechanism for the $\mathrm{Ni}(\mathrm{COD})_{2} / \mathrm{Cs}_{2} \mathrm{CO}_{3} / \mathrm{Et}_{2} \mathrm{Zn}$-catalyzed hydrocarboxylation of styrenes. $^{57}$ 
$\mathrm{FeCl}_{2}$ /bis(iminopyridine)-catalyzed reductive hydrocarboxylation of styrenes has been also reported to proceed under mild conditions ( 1 bar $\mathrm{CO}_{2}$; room temperature; THF) using excess EtMgBr as reductant. ${ }^{59}$ The proposed mechanism (Scheme 13) involves an organomagnesiation step, followed by carboxylation of the resulting secondary Grignard reagent to yield mostly the corresponding $\alpha$-substituted carboxylic acid derivatives. This Fe-based system is only active with ethyl Grignard co-reagents; many other traditional hydride sources $\left(\mathrm{NaBH}_{4}, \mathrm{LiAlH}_{4}, \mathrm{NaHBEt}_{3}\right.$, $\left.n \mathrm{BuLi}, \mathrm{Et}_{2} \mathrm{Zn}, \mathrm{Et}_{3} \mathrm{Al}, i \mathrm{Bu}_{2} \mathrm{AlH}\right)$ were found completely inefficient.

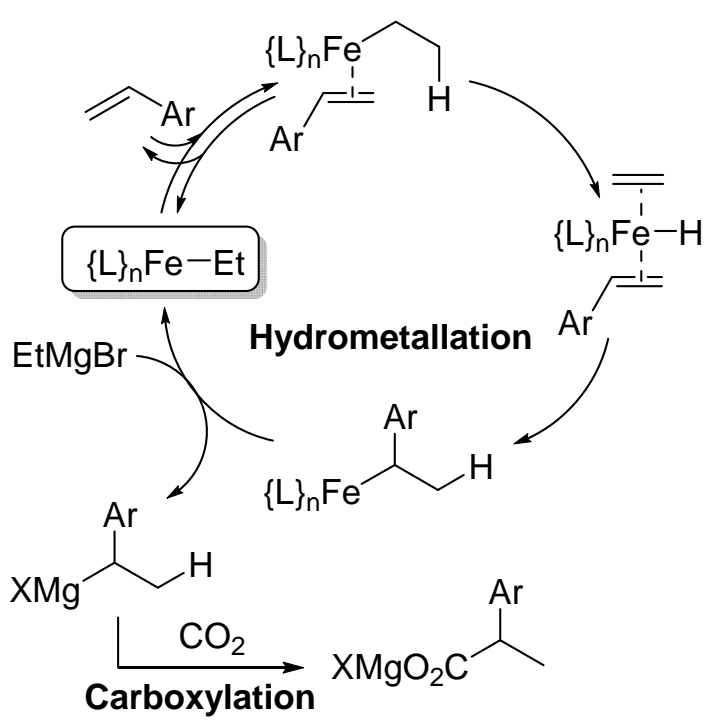

Scheme 13. Proposed mechanism for $\mathrm{FeCl}_{2} /$ bis(iminopyridine)/EtMgBr-catalyzed carboxylation of styrenes. $^{59}$

There are also a few reports on reductive carboxylation of functionalized alkenes: terminal alkene hydroboration followed by $\mathrm{Cu}$-catalyzed carboxylation in the presence of $\mathrm{KO} \mathrm{Bu},{ }^{60}$ and reductive carboxylation of allyl esters and halides on $\mathrm{Ni}$ catalysts carried out using metallic $\mathrm{Zn}$ and Mn powders as stoichiometric reducing agents. ${ }^{61}$

Dienes and alkynes are substantially more reactive substrates that can be converted to the corresponding unsaturated carboxylic acids derivatives. Thus, the ring-closing carboxylation of 
bis(1,3-dienes) ${ }^{62}$ and hydrocarboxylation of 1,3-dienes ${ }^{63}$ and allenes, ${ }^{64}$ catalyzed by Ni and Pd complexes have been reported to proceed in the presence of superstoichiometric amounts of organometallic reagents $\left(\mathrm{R}_{2} \mathrm{Zn}(\mathrm{R}=\mathrm{Et}, \mathrm{Ph})\right.$ and $\mathrm{Et}_{3} \mathrm{Al}$, respectively). Similarly, both terminal and internal alkynes and some functional derivatives have been used in $\mathrm{Ni}$ - and $\mathrm{Cu}$-catalyzed reactions with $\mathrm{CO}_{2}$ in the presence of different reagents $\left(\mathrm{R}_{2} \mathrm{Zn}\right.$ and $\mathrm{RZnX}(\mathrm{R}=\mathrm{Me}, \mathrm{Et}, \mathrm{Bu}, \mathrm{Bn}, \mathrm{Ph} ; \mathrm{X}=\mathrm{Cl}$, $\left.\mathrm{Br}, \mathrm{I}), \mathrm{M}_{2} \mathrm{CO}_{3}(\mathrm{M}=\mathrm{K}, \mathrm{Cs})\right),{ }^{65,66}$ and in related bora- ${ }^{67}$ and silacarboxylation ${ }^{68}$ reactions using $\mathrm{B}_{2}$ (pin) $)_{2} / \mathrm{LiO} t \mathrm{Bu}$ and $\mathrm{Et}_{3} \mathrm{SiB}($ pin) $/ \mathrm{NaOtBu}$ co-reagents. The synthesis of propiolic acids by carboxylation of terminal alkynes in the presence of bases $\mathrm{M}_{2} \mathrm{CO}_{3}(\mathrm{M}=\mathrm{K}, \mathrm{Cs})$ catalyzed by $\mathrm{Cu}(\mathrm{I})$ and $\mathrm{Ag}(\mathrm{I})$ complexes ${ }^{69}$ and heterogeneous Ag-doped MOFs ${ }^{70}$ has been also developed.

The coupling of styrene derivatives with $\mathrm{CO}_{2}$ in $\mathrm{MeOH}$ into the corresponding methyl esters catalyzed by Ni hydrides has been described by Garcia and coworkers. ${ }^{71}$ The proposed hydroesterification mechanism (Scheme 14) parallels that of hydroxycarbonylation (Scheme 2$) ;{ }^{16}$ it also incorporates a step of formation of an acyl-metal intermediate from the corresponding Ni-alkyl species and $\mathrm{CO}$ generated from $\mathrm{CO}_{2} \cdot{ }^{72}$ The $\mathrm{CO}_{2}$ origin of the carbonyl group in the final product has been corroborated by ${ }^{13} \mathrm{C}$ labelling experiments.

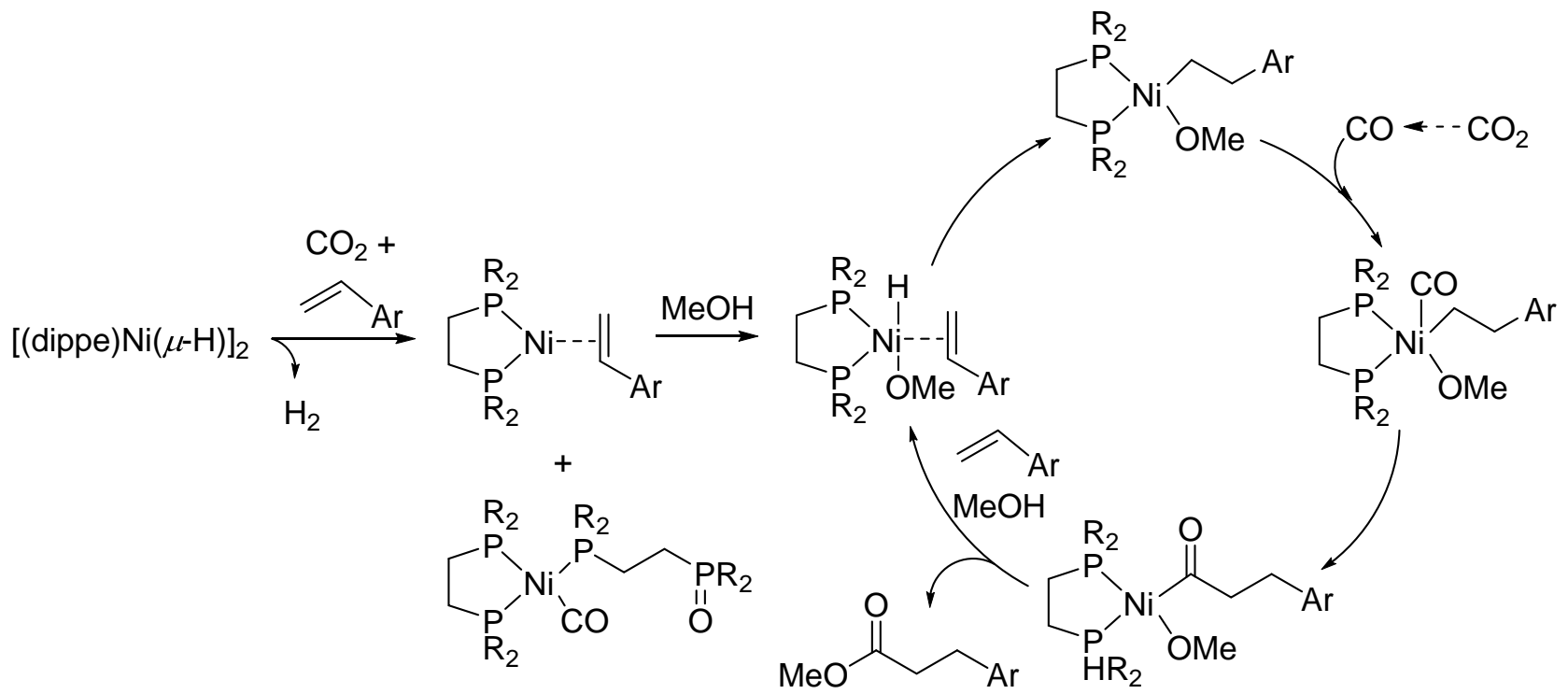

Scheme 14. Proposed mechanism for the Ni-catalyzed hydroesterification of styrenes. ${ }^{71}$ 
A similar mechanistic pathway has been proposed by Beller and coworkers for the Rucatalyzed hydroesterification of many industrially important olefins; ${ }^{73}$ the reduction of $\mathrm{CO}_{2}$ to $\mathrm{CO}$ in $\mathrm{MeOH}$ (solvent) was also suggested.

There are only a few examples describing the use of hydrosilanes as reductants in carboxylation of unsaturated substrates (typically, alkynes). ${ }^{74}$ For example, the hydrocarboxylation of disubstituted alkynes catalyzed by (NHC)CuF (NHC $=N$-heterocyclic carbene) has been reported to proceed under mild conditions $\left(1 \mathrm{~atm} \mathrm{CO}_{2}, 65-100{ }^{\circ} \mathrm{C}\right)$, giving the corresponding silyl esters of $\alpha, \beta$-unsaturated carboxylic acids (Scheme 15). ${ }^{75}$ Stoichiometric studies revealed that the rate-determining step of the process is the insertion of $\mathrm{CO}_{2}$ into the $\mathrm{Cu}-\mathrm{C}$ bond of the alkenyl intermediate. Remarkably, the reaction of the $\mathrm{Cu}(\mathrm{I})$-carboxylate intermediate with hydrosilane occurred readily, already at room temperature; different hydrosilanes have been tested as reducing agents, exhibiting the following order of reactivity: (EtO) $)_{3} \mathrm{SiH} \geq$ PMHS (= polymethylhydrosiloxane $)>(\mathrm{PrO})_{3} \mathrm{SiH}>\mathrm{Ph}_{2} \mathrm{SiH}_{2}$.

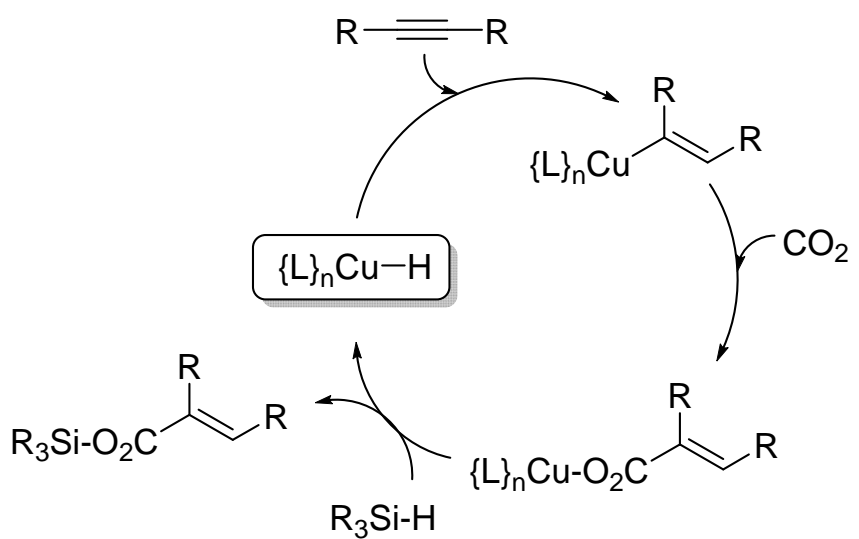

Scheme 15. Proposed mechanism for the $(\mathrm{NHC}) \mathrm{CuF} / \mathrm{R}_{3} \mathrm{SiH}$-catalyzed hydrocarboxylation of alkynes. ${ }^{75}$

\section{Perspectives}


Depending on the nature of the catalytic system used for the carboxylation of alkenes, three distinct types of mechanisms can be operational: (1) a rWGSR-mediated hydroxycarbonylation that affords straightforwardly saturated carboxylic acids; (2) the formation of acrylates via oxidative addition of $\mathrm{CO}_{2}$ and alkene onto a low-valent metal center, followed by $\beta$ - and reductive eliminations steps; (3) the production of metallic salts/organoelemental derivatives of the corresponding saturated acids via an hydrocarboxylation mediated by metal-hydrido or -alkyl species.

For the first process, the key and indispensable step is the rWGSR utilizing $\mathrm{CO}_{2} / \mathrm{H}_{2}$ mixtures as CO surrogates. Since dihydrogen is widely preferred as reductant in organic synthesis and catalysis $^{76}$ as an inexpensive, clean and sustainable reagent, ${ }^{77}$ it obviously grants atom-economy for the given reaction. The use of dihydrogen as reducing agent in this process admittedly limits its applicability to homogeneous catalytic systems that are capable of maintaining efficiently the rWGSR step in the putative catalytic cycle (Scheme 3). While many heterogeneous, both singleand multicomponent systems are known to catalyze this reversible process, ${ }^{78}$ only for a few homogeneous systems (typically based on $\mathrm{Rh}$ and $\mathrm{Ru}$ ) the rWGSR has been proposed to operate as a part of global carbonylation processes utilizing $\mathrm{CO}_{2} / \mathrm{H}_{2}$ mixtures as $\mathrm{CO}$ surrogates. ${ }^{2 \mathrm{a}, \mathrm{j}, 19,20,21}$ In this regard, the identification of other homogeneous catalytic systems, based preferably on more abundant, less expensive metals (Fe, Co, Ni etc) competent for catalyzing the rWGSR under mild conditions, would also be of high industrial relevance. Unfortunately, to date, the complete deficiency of experimental (kinetic) and computational data for this process does not allow a rational optimization/development; identification of the optimal conditions remains still serendipitous.

For the second and third processes, efficient high-energy reductants are mandatory in order to compensate the unfavorable thermodynamics of the carboxylation reactions: (1) for cleavage of the metallacycle in the divalent $\mathrm{Ni}^{(\mathrm{II})} / \mathrm{Pd}^{(\mathrm{II})}$ intermediates formed in the oxidative coupling step of unsaturated hydrocarbon with $\mathrm{CO}_{2}$; and/or (2) for regeneration of the low valent transition metal 
species from the corresponding carboxylate intermediates; and (3) for conversion via transmetallation of metal-carboxylate intermediates to the catalytically active metal-alkyl or hydrido species. These reactions thus result in release of the carboxylate products as metallic $\left(\mathrm{Na}^{+}\right.$, $\mathrm{Zn}^{2+}$ or $\mathrm{Mg}^{2+}$, respectively) salts, which have to be treated acidically in order to recover the corresponding pure carboxylic acids. Therefore, this way of achieving the carboxylation process is plagued by the consumption of a stoichiometric amount of an expensive, difficult-to-handle and waste-generating organometallic reagent.

On the other hand, use of dihydrogen as reductant is hardly compatible with both mechanisms (Schemes 11-13). Indeed, the pivotal step of the reductive carboxylation process, namely, the reduction of metal-carboxylate intermediates with dihydrogen to give the corresponding carboxylic acid and a metal-hydrido species, is thermodynamically difficult $\left(\mathrm{BDE}_{298}(\mathrm{H}-\mathrm{H}\right.$ bond $)=$ $104 \mathrm{kcal} \cdot \mathrm{mol}^{-1}, \mathrm{BDE}_{298}(\mathrm{Si}-\mathrm{H}$ bond $\left.)=80 \mathrm{kcal} \cdot \mathrm{mol}^{-1}\right) .{ }^{79}$

A modified scenario can be envisaged, by implementing reduction with a molecular hydrosilane or the more economically-viable polymethylhydrosiloxane (PMHS); this would provide direct access to valuable carboxylic acid silyl esters. Readily available, easy-to-handle and relatively inexpensive (although admittedly incompatible with the production of commodities) hydrosilanes are widely used as reducing organic agents for many functional groups. ${ }^{80}$ Given the high propensity of hydrosilanes to induce formation of $\mathrm{M}-\mathrm{H}$ bonds in metal complexes via the simultaneous, thermodynamically favored formation of $\mathrm{Si}-\mathrm{O}$ bonds $\left(\mathrm{BDE}_{298}(\mathrm{Si}-\mathrm{O}\right.$ bond $)=190$ $\left.\mathrm{kcal} \cdot \mathrm{mol}^{-1}\right)^{79}$ and their highly tunable reactivity by the substituents at the silicon atom, these are eminently competitive reducing agents to organometallic substrates; they are also a frequent alternative to dihydrogen in many metal-catalyzed processes. PMHS, a low molecular weight $\left(M_{\mathrm{n}}\right.$ $=1,700-3,200 \mathrm{~g} \cdot \mathrm{mol}^{-1}$ ) polymeric byproduct of the silicone industry, can also be used as a very cheap and environmentally friendly reducing agent. PMHS is more air- and moisture-stable than other hydrosilanes and can be stored for long periods of time without loss of activity. The mechanism of action and reactivity pattern of PMHS are the same as those featured by usual 
hydrosilanes; application of PMHS for reduction of $\mathrm{C}=\mathrm{O}$ groups in aldehydes and ketones has been reported. ${ }^{81}$ The envisioned mechanism for reductive carboxylation of unsaturated hydrocarbons with hydrosilanes (Scheme 16, Cycle A) is composed of a series of elementary chemical reactions which, individually, are all well-documented: (i) alkene insertion into the $\mathrm{M}-\mathrm{H}$ bond of active metal-hydrido species 1 to afford metal-alkyl 2; ${ }^{82}$ (ii) insertion of $\mathrm{CO}_{2}$ into the $\mathrm{M}$-alkyl bond of 2 yielding metal-carboxylate $3 ;^{8}$ (iii) a transelementation reaction of $\mathbf{3}$ with a hydrosilane delivering the corresponding alkyl silyl ester $4 .^{83}$ A competing mechanism may be envisioned (Scheme 16, Cycle B), which involves rapid insertion of $\mathrm{CO}_{2}$ into the $\mathrm{M}-\mathrm{H}$ bond of $\mathbf{1}$ to give a metal-formate intermediate of the type 5, which upon reaction with the hydrosilane would release the corresponding silyl formate 6 as a by-product besides the desired 4 . The latter process, that is hydrosilylation of $\mathrm{CO}_{2}$, is well documented in the literature and it is known to be catalyzed by complexes and salts of non-transition elements. ${ }^{3}$

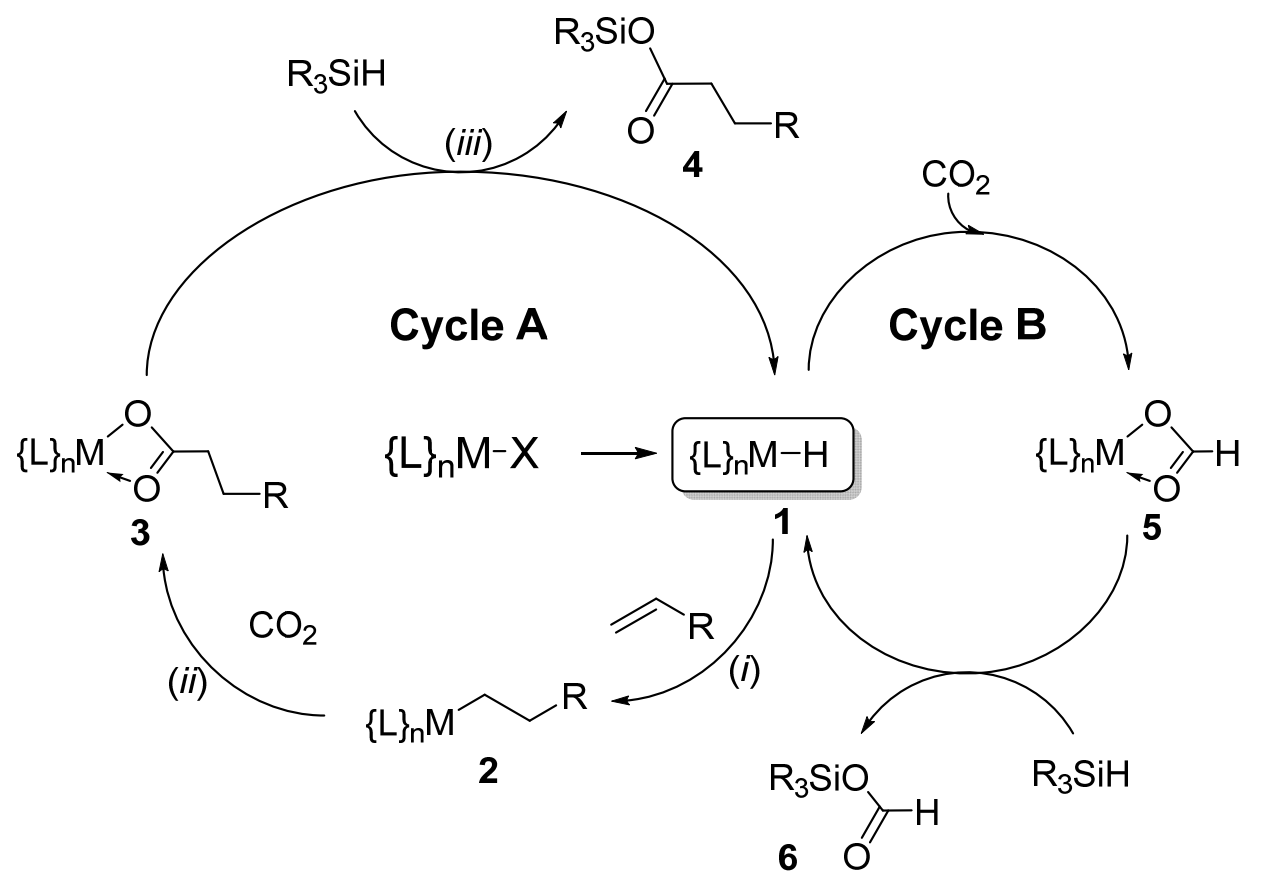

Scheme 16. Putative catalytic cycle (A) for the formation of silyl esters by reductive carboxylation of alkenes, and $\mathrm{CO}_{2}$ hydrosilylation (B) as anticipated side reaction. 
In both cases (Scheme 16, Cycles A and B), hydrolysis of silyl esters 4 and 6 under mild conditions in a distinct, final workup step shall yield the corresponding alkyl-carboxylic and formic acids, respectively, and nontoxic (poly)siloxane byproducts (use of PMHS). However, silyl esters primarily resulting from the above global process are also much valuable precursors and synthetic intermediates. For instance, they are employed as intermediates and cross-linking reagents in the synthesis of poly(silyl esters), some biodegradable polymers widely used for medical applications (drug delivery systems, surgical devices, recyclable materials). ${ }^{84}$ Synthesis of silyl esters generally relies on condensation of carboxylic acids with chlorosilanes with concomitant elimination of $\mathrm{HCl}^{85}$ An alternative synthetic protocol exists, which is based on dehydrogenative coupling of carboxylic acids with hydrosilanes catalyzed by transition metal complexes $(\mathrm{Ru}-\mathrm{Pd}, \mathrm{Pt}, \mathrm{Cu}) .{ }^{84 b, \mathrm{c}}$

\section{Conclusions}

In this Perspective, we have highlighted advances and recent breakthroughs in the "direct" catalytic synthesis of carboxylic acids and their derivatives starting from unsaturated hydrocarbons (alkenes, alkynes, dienes) and $\mathrm{CO}_{2}$. All of the existing systems are plagued either by a poor catalytic productivity and/or the use of expensive and waste-generating stoichiometric reductants. Efforts must be paid to optimize the cost, safety and global sustainability of such processes. These objectives could be achieved by two interlinked approaches: (1) implementation of catalytic systems that are competent for carboxylation of unsaturated hydrocarbons (alkenes) using $\mathrm{H}_{2}$ as reducing agent under mild conditions (temperature, pressure); and/or (2) implementation of relatively inexpensive and efficient reducing agents in the catalytic systems (e.g., molecular hydrosilanes or the polymeric analogue, polymethylhydrosiloxane (PMHS)). Understanding of the nature and role of key intermediates and mechanisms of $\mathrm{CO}_{2}$ activation from experimental approaches and multi-scale theoretical simulations is the key for elaborating processes that enable efficient transformation of $\mathrm{CO}_{2}$ into value-added chemicals. This is also of high interest for future renewable energy technologies and addressing the global issue of energy transition. 


\section{REFERENCES}

(a) Carbon Dioxide as Chemical Feedstock (Ed. Aresta, M.), Wiley-VCH, 2010, pp 414. (b) Activation of carbon dioxide, in New and Future Developments in Catalysis (Ed. Suib, S. L.), Elsevier, 2013, pp 644.

2 (a) O. Liu, L. Wu, R. Jackstell, M. Beller, Nat. Commun., 2015, 6, doi:10.1038/ncomms6933.

(b) P. Dixneuf, Catal. Lett., 2015, 145, 360-372. (c) M. Aresta, A. Dibenedetto, A. Angelini, Chem. Rev., 2014, 114, 1709-1742. (d) N. Von der Assen, P. Voll, M. Peters, A. Bardow, Chem. Soc. Rev., 2014, 43, 7982-7984. (e) A. Dibenedetto, A. Angelini, P. Stufano, J. Chem. Technol. Biotechnol., 2014, 89, 334-353. (f) A. Appel, J. E. Bercaw, A. B. Bocarsly, H. Dobbek, D. L. DuBois, M. Dupuis, J. G. Ferry, E. Fujita, R. Hille, P. J. A. Kenis, C. A. Kerfeld, R. H. Morris, C. H. F. Peden, A. R. Portis, S. W. Ragsdale, T. B. Rauchfuss, J. N. H. Reek, L. C. Seefeldt, R. K. Thauer, G. L. Waldrop, Chem. Rev., 2013, 113, 6621-6658. (g) S. N.; Riduan, Y. Zhang, Dalton Trans., 2010, 39, 3347-3357. (h) M. Cokoja, C. Bruckmeier, B. Rieger, W. A. Hermann, F. E. Kuhn, Angew. Chem. Int. Ed., 2011, 50, 8510-8537. (i) K. Huang, C.-L. Sun, Z.-S. Shi, Chem. Soc. Rev., 2011, 40, 2435-2452. (j) T. Sakakura, J.-C. Choi, H. Yasuda, H. Chem. Rev., 2007, 107, 2365-2387. (k) Aresta, M.; Dibenedetto, A. Dalton Trans. 2007, 2975-2992. (1) D. Walther, M. Ruben, S. Rau, Coord. Chem. Rev., 1999, 182, 67100. (m) P. Braunstein, D. Matt, D. Nobel, Chem. Rev., 1988, 88, 747-764.

3 (a) F. Fernandez-Alvarez, A. M. Aitani, L. A. Oro, Catal. Sci. Technol., 2014, 4, 611-624. (b)

F.-G. Fontaine, M.-A. Courtemanche, M.-A. Légaré, Chem. Eur. J., 2014, 20, 2990-2996. (c) W. Wang, S. Wang, X. Ma, J. Gong, Chem. Soc. Rev., 2011, 40, 3703-3727. (d) P. G. Jessop, F. Joo, C.-C. Tai, Coord. Chem. Rev., 2004, 248, 2425-2442. (e) P. G. Jessop, T. Ikariya, R. Noyori, Chem. Rev., 1999, 99, 475-493. (f) P. G. Jessop, T. Ikariya, R. Noyori, Chem. Rev., $1995,95,259-272$. 
$4 \quad$ W. Zhang, X. Lu. Chin. J. Catal., 2012, 33, 745-756.

5 B. Yu, Z.-F. Diao, C.-X. Guo, L.-N. He, Journal of $\mathrm{CO}_{2}$ Utilization, 2013, 1, 60-68.

6 (a) S. Paul, Y. Zhu, C. Romain, R. Brooks, P. K. Saini, C. K. Williams, Chem. Commun., 2015, 51, 6459-6479. (b) M. I. Childers, J. M. Longo, N. J. Van Zee, A. M. LaPointe, G. W. Coates, Chem. Rev., 2014, 114, 8129-8152. (c) N. Ikpo, J. C. Flogeras, F. M. Kerton, Dalton Trans., 2013, 42, 8998-9006. (d) M. R. Kember, A. Buchard, C. K. Williams, Chem. Commun., 2011, 47, 141-163. (e) D. J. Darensbourg, Chem. Rev. 2007, 107, 2388-2410. (f) H. Sugimoto, S. Inoue, J. Polym. Sci. A: Polym. Chem., 2004, 42, 5561-5573. (g) G. W. Coates, D. R. Moore, Angew. Chem. Int. Ed., 2004, 43, 6618-6639.

7 (a) M. Drees, M. Cokoja, F. E. Kuhn, ChemCatChem, 2012, 4, 1703-1712. (b) D. J. Darensbourg, A. D. Yeung, Polym. Chem., 2014, 5, 3949-3962.

8 (a) X. Yin, J. R. Moss, Coord. Chem. Rev., 1999, 181, 27-59. (b) W. Leitner, Coord. Chem. Rev., 1996, 153, 257-284. (c) K. K. Pandey, Coord. Chem. Rev., 1995, 140, 37-114. (d) M. E. Vol'pin, I. S. Kolomnikov, Pure Appl. Chem., 1973, 33, 567-581.

9 (a) D. W. Stephan, G. Erker, Angew. Chem. Int. Ed., 2015, 54, doi: 10.1002/anie.201409800. (b) K. Revunova, G. I. Nikonov, Dalton Trans., 2015, 44, 840-866. (c) B. P. Spigarelli, S. K. Kawatra, Journal of $\mathrm{CO}_{2}$ Utilization, 2013, 1, 69-87. (d) E. B. Stechel, J. E. Miller, Journal of $\mathrm{CO}_{2}$ Utilization, 2013, 1, 28-36. (e) Special Issue: Metal Mediated Transformation of $\mathrm{CO}_{2}$, Polyhedron, 2012, 32. (f) Special Issue: Fifth International Conference on Carbon Dioxide Utilization (ICCDU V), Appl. Organomet. Chem., 2001, 15.

10 Ethylene is the largest volume organic chemical produced in the world (140 MT/y), followed by propylene (87 MT/y), see: E. B. Stechel, J. E. Miller, Journal of $\mathrm{CO}_{2}$ Utilization, 2013, 1, 28-36.

11 Industrial organic chemicals $-2^{\text {nd }}$ ed., H. A. Wittcoff, B. G. Reuben, J. S. Plotkin, Wiley-VCH, 2004, pp 662.

12 K. Muller, L. Mokrushina, W. Arlt, Chem. Ing. Tech., 2014, 86, 497-503. 
13 E. M. Wilcox, G. W. Roberts, J. J. Spivey, Cat. Today, 2003, 88, 83-90.

14 B. R. J. Smith, M. Loganathan, M. S. Shantha, Int. J. Chem. React. Eng., 2010, 8, 1542-6580.

15 (a) C. Tortosa-Estorach, N. Ruiz, A. M. Masdeu-Bulto, Chem. Commun. 2006, 2789-2791. (b)

C. Tortosa-Estorach, A. Orejon, N. Ruiz, A. M. Masdeu-Bulto, G. Laurenczy, Eur. J. Inorg. Chem., 2008, 3524-3531. (c) S. Tilloy, E. Monflier, F. Bertoux, Y. Castanet, A. Mortreux, New. J. Chem., 1997, 529-531. (d) E. Monflier, S. Tilloy, F. Bertoux, Y. Castanet, A. Mortreux, New. J. Chem., 1997, 857-859. (e) H. Alper, J. B. Woell, B. Despeyroux, D. J. H. Smith, J. Chem. Soc. Chem. Commun., 1983, 1270-1271. (f) D. M. Fenton, J. Org. Chem., $1973,3192-3198$.

I. Del Rio, C. Claver, P. W. N. M. Leeuwen, Eur. J. Inorg. Chem., 2001, 2719-2738.

In Pd-catalyzed hydrocarbonylation of ethylene to diethyl ketone, WGSR serves as a source of $\mathrm{H}_{2}$, while the concomitantly produced $\mathrm{CO}_{2}$ remains intact: V. N. Zudin, V. D. Chinakov, V. M. Nekipelov, V. A. Rogov, V. A. Likholobov, Yu. I. Yermakov, J. Mol. Cat., 1989, 52, 27-48.

18 A. L. Lapidus, S. D. Pirojkov, A. A. Koryakin, Bull. Acad. Sci. USSR, Div. Chem. Sci., 1978, 2514-2516 and references cited therein.

19 T. G. Ostapowicz, M. Schmitz, M. Krystof, J. Klankermayer, W. Leitner, Angew. Chem. Int. Ed., 2013, 52, 12119-12123.

20 (a) K. Tominaga, T. Sasaki, Cat. Commun., 2000, 1, 1-3. (b) K. Tominaga, Catal. Today, 2006, $115,70-72$.

Q. Liu, L. Wu, I. Fleisher, D. Selent, R. Franke, R. Jackstell, M. Beller, Chem. Eur. J., 2014, $20,6888-6894$.

J. Bringmann, E. Dinjus, Appl. Organomet. Chem., 2001, 15, 135-140.

23 (a) S. Derien, E. Dunach, J. Perichon, J. Am. Chem. Soc., 1991, 113, 8447-8454. (b) E. Dunach, J. Perichon, J. Organomet. Chem., 1988, 352, 239-246. 177, 303-309. 
25 Acrylic acid is produced by a multi-step oxidation of propylene. The market of acrylic acid derivatives is around $2.5 \mathrm{MT} /$ year with annual expansion rate of $4 \%$, see: ref. $2 \mathrm{c}$.

I. Papai, G. Schubert, I. Mayer, G. Besenyei, M. Aresta, Organometallics, 2004, 23, 52525259.

A revisited mechanism has been described recently: P. N. Plessow, A. Schafer, M. Limbach, P. Hofmann, Organometallics, 2014, 33, 3657-3668.

(a) H. Hoberg, D. Schaefer, J. Organomet. Chem., 1982, 236, C28-C30. (b) H. Hoberg, D. Schaefer, J. Organomet. Chem., 1983, 251, C51-C53. (c) H. Hoberg, D. Schaefer, J. Organomet. Chem., 1984, 276, 99-107. (d) H. Hoberg, Y. Peres, A. Milchereit, J. Organomet. Chem., 1986, 307, C38-C40. (e) H. Hoberg, M. Minato, J. Organomet. Chem., 1991, 406, C25C28.

29 H. Hoberg, K. Jenni, K. K. Angermund, C. Kruger, Angew. Chem. Int. Ed., 1987, 26, 153-155.

30 A. Musco, C. Perego, V. Tartiari, Inorg. Chim. Acta., 1978, 28, L147-L148.

31 Z. R. Greenburg, D. Jin, P. G. Williard, W. H. Bernskoetter, Dalton Trans., 2014, 43, 1599015996.

32 A thermally stable metallalactone complex of Ti(IV) has been reported to be the product of the reaction of the parent $\mathrm{Ti}(\mathrm{II})$ precursor $\mathrm{Cp}_{2}{ }_{2} \mathrm{Ti}\left(\eta^{2}-\mathrm{C}_{2} \mathrm{H}_{4}\right)$ and $\mathrm{CO}_{2}$ : S. A. Cohen, J. E. Bercaw, Organometallics, 1985, 4, 1006-1014.

$33 \mathrm{Zr}$ (II)-metallocenes have been used for the synthesis of the corresponding $\operatorname{Zr}(\mathrm{IV})$ zirconalactone complexes: (a) H. G. Alt, C. E. Denner, J. Organomet. Chem., 1990, 390, 53-60. (b) K. Yamashita, N. Chatani, Synlett, 2005, 919-922.

R. Fischer, J. Langer, A. Malassa, D. Walther, H. Gorls, G. Vaughan, Chem. Commun., 2006, $2510-2512$

H. Hoberg, A. Ballesteros, J. Organomet. Chem., 1991, 411, C11-C18.

H. Hoberg, Y. Peres, C. Kruger, Y.-H. Tsay, Angew. Chem. Int. Ed., 1987, 26, 771-773. 
37 (a) Y. Sasaki, Y. Inoue, H. Hashimoto, J. C. S. Chem. Commun., 1976, 605-606. (b) A. Musco, C. Perego, V. Tartiari, Inorg. Chim. Acta, 1978, 28, L147-L148. (c) H. Hoberg, S. Gross, A. Milchereit, Angew. Chem. Int. Ed., 1987, 26, 571-572. (d) P. Braunstein, D. Matt, D. Nobel, J. Am. Chem. Soc., 1988, 110, 3207-3212. (e) E. Dinjus, W. Leitner, Appl. Organomet. Chem., 1995, 9, 43-50. (f) S. Pitter, E. Dinjus, J. Mol. Cat. A: Chem., 1997, 125, 39-45. (g) A. Behr, M. Becker, Dalton Trans., 2006, 4607-4613. (h) R. Nakano, S. Ito, K. Nozaki, Nat. Chem., $2014,6,325-331$.

(a) T. Tsuda, S. Morikawa, R. Sumiya, T. Saegusa, J. Org. Chem., 1988, 53, 3140-3145. (b) J. Louie, J. E. Gibby, M. V. Farnworth, T. N. Tekavec, J. Am. Chem. Soc., 2002, 124, 1518815189.

D. C. Graham, C. Mitchell, M. I. Bruce, G. F. Metha, J. H. Bowie, M. A. Buntine, Organometallics, 2007, 26, 6784-6792.

C. Bruckmeier, M. W. Lehenmeier, R. Reichardt, S. Vagin, B. Rieger, Organometallics, 2010, 29, 2199-2202.

S. Y. T. Lee, M. Cokoja, M. Drees, Y. Li, J. Mink, W. A. Herrmann, F. E. Kuhn, ChemSusChem, 2011, 4, 1275-1279.

42 W. Guo, C. Michel, R. Schiedernoch, R. Wischert, X. Xu, P. Sautet, Organometallics, 2014, 33, 6369-6380.

P. N. Plessow, L. Weigel, R. Linder, A. Schafer, F. Rominger, M. Limbach, P. Hofmann, Organometallics, 2013, 32, 3327-3338.

D. Jin, T. J. Schmeier, P. G. Williard, N. Hazari, W. H. Bernskoetter, Organometallics, 2013, 32, 2152-2159.

D. Jin, P. G. Williard, N. Hazari, W. H. Bernskoetter, Chem. Eur. J., 2014, 20, 3205-3211.

R. A. Zarkesh, M. D. Hopkins, R. F. Jordan, Eur. J. Inorg. Chem., 2014, 5491-5494.

E. M. O’Brien, E. A. Bercot, T. Rovis, J. Am. Chem. Soc., 2003, 125, 10498-10499. 
48 (a) R. Alvarez, E. Carmona, D. J. Cole-Hamilton, A. Galindo, E. Gutierrez-Puebla, A. Monge, M. L. Poveda, C. Ruiz, J. Am. Chem. Soc., 1985, 107, 5529-5531. (b) R. Alvarez, E. Carmona, A. Galindo, E. Gutierrez, J. M. Marin, A. Monge, M. L. Poveda, C. Ruiz, J. M. Savariault, Organometallics, 1989, 8, 2430-2439. (c) A. Galindo, A. Pastor, P. J. Perez, E. Carmona, Organometallics, 1993, 12, 4443-4451.

G. Schubert, I. Papai, J. Am. Chem. Soc., 2003, 125, 14847-14858.

50 Y. Zhang, B. S. Hanna, A. Dineen, P. G. Williard, W. H. Bersnkoetter, Organometallics, 2013, 32, 3969-3979.

(a) B. S. Hanna, A. D. MacIntosh, S. Ahn, B. T. Tyler, G. T. R. Palmore, P. G. Williard, W. H. Bersnkoetter, Organometallics, 2014, 33, 3425-3432. (b) W. H. Bersnkoetter, B. T. Tyler, Organometallics, 2011, 30, 520-527.

J. M. Wolfe, W. H. Bernskoetter, Dalton. Trans., 2012, 41, 10763-10768.

M. Aresta, C. Pastore, P. Giannoccaro, G. Kovacs, A. Dibenedetto, I. Papai, Chem. Eur. J., 2007, 13, 9028-9034.

(a) M. L. Lejkowski, R. Lindler, T. Kageyama, G. E. Bodizs, P. N. Plessow, I. B. Muller, A. Schafer, F. Rominger, P. Hofman, C. Futter, S. A. Schunk, M. Limbach, Chem. Eur. J., 2012, 18, 14017-14025. (b) C. Hendriksen, E. A. Pidko, G. Yang, B. Schaffner, D. Vogt, Chem. Eur. J., 2014, 20, 12037-12040. (c) N. Huguet, I. Jevtovikj, A. Gordillo, M. L. Lejkowski, R. Lindler, M. Bru, A. Y. Khalimon, F. Rominger, S. A. Schunk, P. Hofman, M. Limbach, Chem. Eur. J., 2014, 20, 16858-16862.

G. Yang, B. Schaffner, M. Blug, E. J. M. Hensen, E. A. Pidko, ChemCatChem, 2014, 6, 800807. J. B. Johnson, T. Rovis, Acc. Chem. Res., 2008, 41, 327-338.

C. M. Williams, J. B. Johnson, T. Rovis, J. Am. Chem. Soc., 2008, 130, 14936-14937.

R. Yuan, Z. Lin, Organometallics, 2014, 33, 7147-7156.

M. D. Greenhalgh, S. P. Thomas, J. Am. Chem. Soc., 2012, 134, 11900-11903. 
60 H. Ohmiya, M. Tanabe, M. Sawamura, Org. Lett. 2011, 13, 1086-1088.

61 (a) T. Moragas, J. Cornella, R. Martin, J. Am. Chem. Soc. 2014, 136, 17702-17705. (b) X. Wang, Y. Liu, R. Martin, J. Am. Chem. Soc. 2015, 137, doi: 10.1021/jacs.5b03340.

62 (a) M. Takimoto, M. Mori, J. Am. Chem. Soc., 2002, 124, 10008-10009. (b) M. Takimoto, Y. Nakamura, K. Kimura, M. Mori, J. Am. Chem. Soc., 2008, 126, 5956-5957.

63 (a) M. Takimoto, M. Mori, J. Am. Chem. Soc., 2001, 123, 2895-2896. (b) J. Takaya, K. Sasano, N. Iwasawa, Org. Lett., 2011, 13, 1698-1701.

J. Takaya, N. Iwasawa, J. Am. Chem. Soc., 2008, 130, 15254-15255.

(a) M. Takimoto, K. Shimizu, M. Mori, Org. Lett., 2001, 3, 3345-3347. (b) K. Shimizu, M. Takimoto, Y. Sato, M. Mori, Org. Lett., 2005, 7, 195-197. (c) M. Mori, Eur. J. Inorg. Chem., 2007, 4981-4993. (d) D. Yu, Y. Zhang, PNAS, 2005, 107, 20184-20189. (e) S. Li, S. Ma, Org. Lett., 2011, 13, 6046-6049. (f) S. Li, W. Yuan, S. Ma, Angew. Chem. Int. Ed., 2011, 50, 25782582.

L. J. Goossen, N. Rodriguez, F. Manjolinho, P. P. Lange, Adv. Synth. Catal., 2010, 352, $2913-$ 2917.

L. Zhang, J. Cheng, B. Carry, Z. Hou, J. Am. Chem. Soc., 2012, 134, 14314-14317.

T. Fujihara, Y. Tani, K. Semba, J. Terao, Y. Tsuji, Angew. Chem. Int. Ed., 2012, 51, $11487-$ 11490. 8207. (b) L. Gonzalez-Sebastian, M. Flores-Alamo, J. J. Garcia, Dalton Trans., 2011, 40, 91169122.

F. Manjolinho, M. Arndt, K. Gossen, L. J. Goossen, ACS Catal., 2012, 2, 2014-2021.

X.-H. Liu, J.-G. Ma, Z. Niu, G.-M. Yang, P. Cheng, Angew. Chem. Int. Ed., 2015, 54, 998-991.

(a) L. Gonzalez-Sebastian, M. Flores-Alamo, J. J. Garcia, Organometallics, 2012, 31, 8200-

A. Behr, U. Kanne, W. Keim, J. Mol. Cat., 1986, 35, 19-28.

L. Wu, Q. Liu, I. Fleisher, R. Jackstell, M. Beller, Nat. Commun. 2014, 5, 3091-3096.

Y. Zhang, S. N. Riduan, Angew. Chem. Int. Ed., 2011, 50, 6210-6212. 
75 T. Fujihara, T. Xu, K. Semba, J. Terano, Y. Tsuji, Angew. Chem. Int. Ed., 2011, 50, 523-527.

(a) Organic Chemistry $\quad$ Portal, http://www.organicchemistry.org/chemicals/reductions/hydrogen.shtm. (b) R. J. Rahaim Jr., R. E. Maleczka Jr., Org. Lett., 2011, 13, 584-587. (c) T. Mizuta, S. Sakaguchi, Y. Ishii, Y. J. Org. Chem., 2005, 70, 2195-2199.

77 (a) I. Dincer, C. Acar, International journal of Hydrogen Energy, 2015, doi:10.1016/j.ijhydene.2014.12.035. (b) P. Haussinger, R. Lohmuller, A. M. Watson, in "Hydrogen, 1. Properties and Occurrence". Ullmann's Encyclopedia of Industrial Chemistry, 2011,doi:10.1002/14356007.a13_297.pub2.

(a) W. Wang, S. Wang, X. Ma, J. Gong, Chem. Soc. Rev. 2011, 40, 3703-3727. (b) B. R. J. Smith, M. Loganathan, M. S. Shantha, Int. J. Chem. React. Eng. 2010, 8, 1-32.

B. D. Darvent, Nat. Stand. Ref. Data Ser., Nat. Bur. Stand. (U.S.), 1970, p. 52.

80

Organic

Chemistry

Portal,

http://www.organic-

chemistry.org/chemicals/reductions/silanes.shtm.

81 (a) S. Werkmeister, K. Junge, M. Beller, M. Org. Process Res. Dev., 2014, 18, 289-302. (b) H. Mimoun, J. Org. Chem., 1999, 64, 2582-2589.

82 This reaction constitutes the principal step of the mechanism of polymerization of alkenes using Ziegler-Natta, metallocene and post-metallocene catalysts: J. A. Gladysz, Special issue: Frontiers in Metal-Catalyzed Polymerization, Chem. Rev. 2000, 100, 1167.

To our knowledge, this reaction has been intentionally substantiated only in a few cases: (a) hydrosilane-mediated reduction of Ir-carboxylate complexes into the corresponding hydrides, M. A. Esteruelas, O. Nurnberg, M. Olivan, L. A. Oro, H. Werner, Organometallics, 1993, 12, 3264-3272; (b) quantitative formation of silyl esters from the parent U(III)-carboxylates by $\mathrm{Me}_{3} \mathrm{SiX}$ halides $(\mathrm{X}=\mathrm{Cl}, \mathrm{I})$ : E. M. Matson, W. P. Forrest, P. Fanwick, S. C. Bart, J. Am. Chem. Soc., 2011, 133, 4948-4954; (c) alkoxide and alkylperoxy group transfer reactions from $\{L\}_{n} Z n-O R$ and $\{L\}_{n} Z n-O O R$ complexes to organosilanes have been reported to yield 
selectively the corresponding $\{\mathrm{L}\}_{\mathrm{n}} \mathrm{Zn}-\mathrm{H}$ and $\mathrm{RO}-\mathrm{SiR}_{3}{ }_{3} / \mathrm{ROO}-\mathrm{SiR}_{3}{ }_{3}$ products, respectively: W. Sattler, G. Parkin, G. J. Am. Chem. Soc., 2011, 133, 9708-9711. (d) D. Mukherjee, R. R. Thompson, A. Ellern, A. D. Sadow, ACS Catal. 2011, 1, 698-702. (e) D. Mukherjee, A. Ellern, A. D. Sadow, J. Am. Chem. Soc., 2012, 134, 13018-13026.

84 (a) G.-B. Liu, H.-Y. Zhao, Beilstein J. Org. Chem., 2008, 4, 1-6 and references therein cited. (b) M. Chauhan, B. P. S. Chauhan, P. Boudjouk, Org. Lett., 2000, 2, 1027-1029 and references therein cited. (c) J.-M. Weinberg, S. P. Gitto, K. L. Wooley, Macromolecules, 1998, 31, 15-21. 85 Heldmann, D. K.; Stohrer, J.; Zauner, R. Synlett 2002, 1919-1921. 